\title{
Report on simulation models of solar envelope components
}

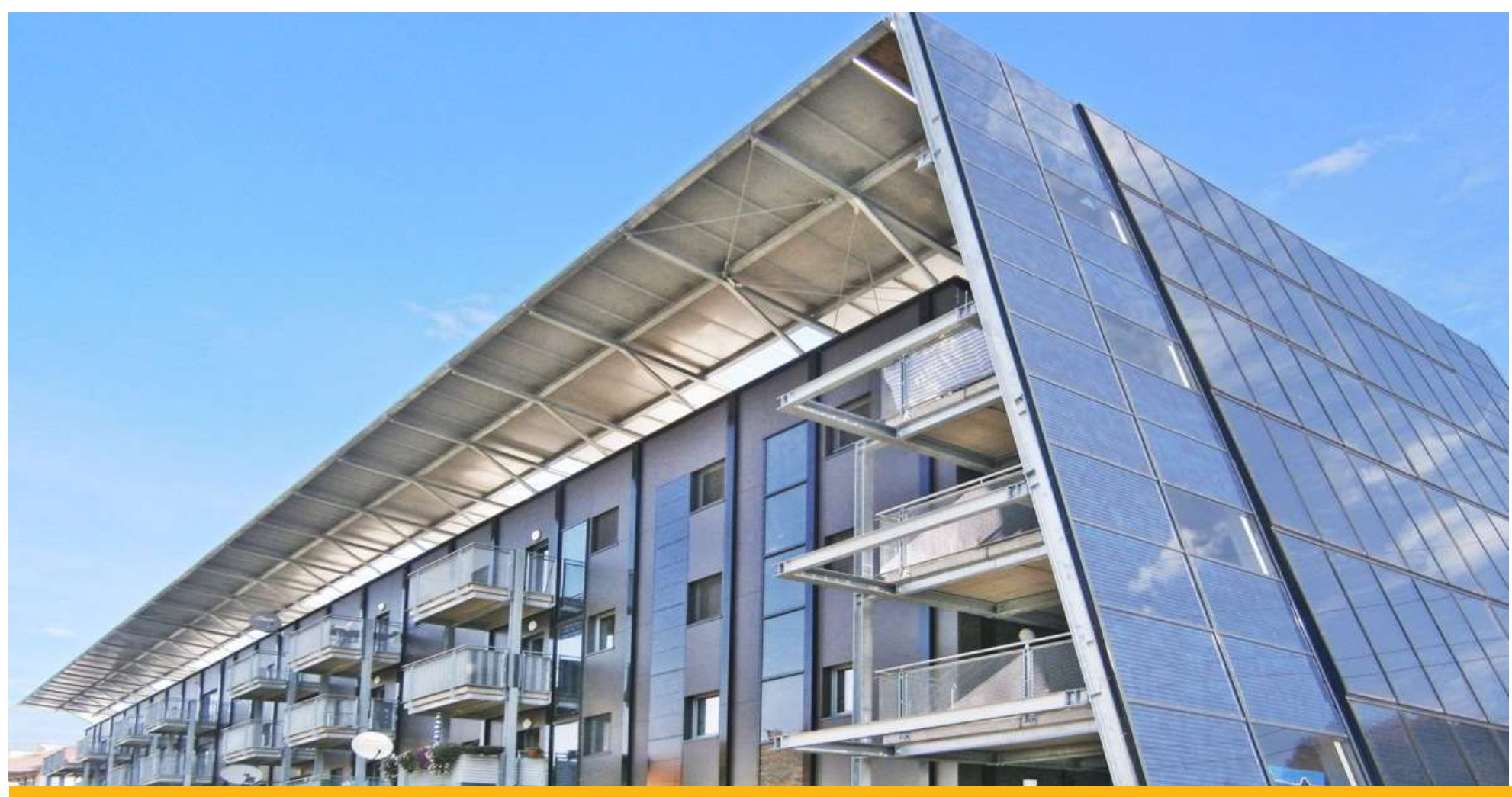

IEA SHC TASK 56 | Building Integrated Solar Envelope Systems for HVAC and Lighting 


\title{
Report on simulation models of solar envelope components
}

\author{
Deliverable DB.4
}

Editor: Christoph Maurer (Fraunhofer ISE)

\author{
Authors: \\ Ellika Taveres-Cachat (NTNU \& Sintef) \\ Roel C.G.M. Loonen (Eindhoven University of Technology) \\ Johannes Eisenlohr (Fraunhofer ISE) \\ Francesco Goia (NTNU) \\ Christoph Maurer (Fraunhofer ISE)
}

December 2019

DB.4, \#DOI: 10.18777/ieashc-task56-2019-0002

The contents of this report do not necessarily reflect the viewpoints or policies of the International Energy Agency (IEA) or its member countries, the IEA Solar Heating and Cooling Technology Collaboration Programme (SHC TCP) members or the participating researchers. 
The Solar Heating and Cooling Technology Collaboration Programme was founded in 1977 as one of the first multilateral technology initiatives ("Implementing Agreements") of the International Energy Agency. Its mission is "To enhance collective knowledge and application of solar heating and cooling through international collaboration to reach the goal set in the vision of solar thermal energy meeting $50 \%$ of low temperature heating and cooling demand by 2050."

The members of the IEA SHC collaborate on projects (referred to as Tasks) in the field of research, development, demonstration (RD\&D), and test methods for solar thermal energy and solar buildings.

Research topics and the associated Tasks in parenthesis include:

- Solar Space Heating and Water Heating (Tasks 14, 19, 26, 44, 54)

- Solar Cooling (Tasks 25, 38, 48, 53)

- Solar Heat for Industrial or Agricultural Processes (Tasks 29, 33, 49, 62, 64)

- Solar District Heating (Tasks 7, 45, 55)

- Solar Buildings/Architecture/Urban Planning (Tasks 8, 11, 12, 13, 20, 22, 23, 28, 37, 40, 41, 47, 51, 52, 56, 59,63 )

- $\quad$ Solar Thermal \& PV (Tasks $16,35,60)$

- Daylighting/Lighting (Tasks 21, 31, 50, 61)

- $\quad$ Materials/Components for Solar Heating and Cooling (Tasks 2, 3, 6, 10, 18, 27, 39)

- $\quad$ Standards, Certification, and Test Methods (Tasks 14, 24, 34, 43, 57)

- $\quad$ Resource Assessment (Tasks 1, 4, 5, 9, 17, 36, 46)

- $\quad$ Storage of Solar Heat (Tasks 7, 32, 42, 58)

In addition to our Task work, other activities of the IEA SHC include our:

$>$ International Conference on Solar Heating and Cooling for Buildings and Industry

$>$ SHC Solar Academy

$>$ Solar Heat Worldwide annual statics report

> Collaboration with solar thermal trade associations

\section{Country Members}

Australia

Austria

Belgium

Canada

China

Denmark

European Commission

\section{Sponsor Members}

European Copper Institute International Solar Energy Society CCREEE

EACREEE

$\begin{array}{ll}\text { France } & \text { South Africa } \\ \text { Germany } & \text { Spain } \\ \text { Italy } & \text { Sweden } \\ \text { Netherlands } & \text { Switzerland } \\ \text { Norway } & \text { Turkey } \\ \text { Portugal } & \text { United Kingdom } \\ \text { Slovakia } & \end{array}$

\section{ECREEE}

PCREEE

RCREEE

SACREEE

For more information on the IEA SHC work, including many free publications, please visit www.iea-shc.org 


\section{Contents}

CONTENTS ....................................................................................................................................... III

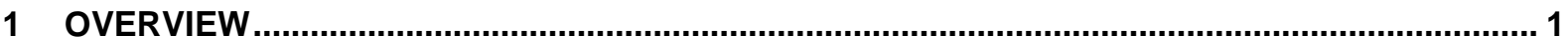

2 REVIEW OF SIMULATION MODELS ............................................................................... 2

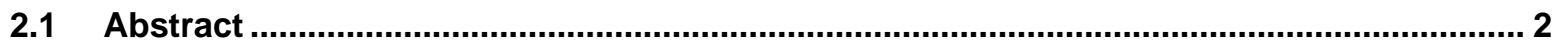

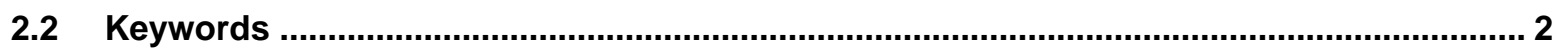

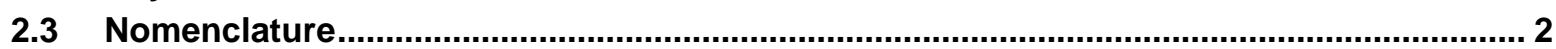

2.4 Introduction ................................................................................................................ 2

2.5 Framework for choosing BISE modelling approaches................................................ 4

2.6 Modelling approaches for building integrated solar envelopes....................................... 5

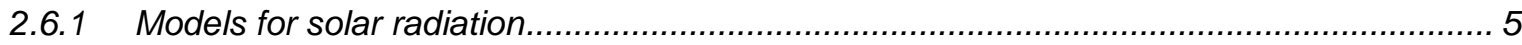

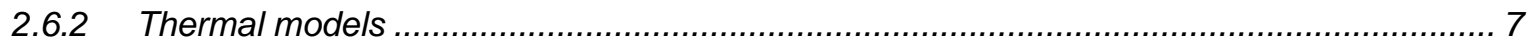

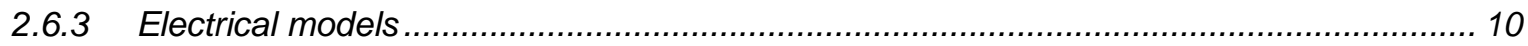

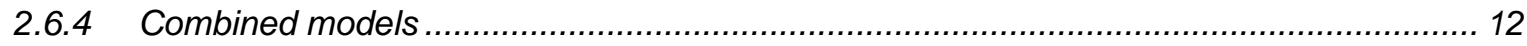

2.7 BISE modelling in case studies ....................................................................................... 13

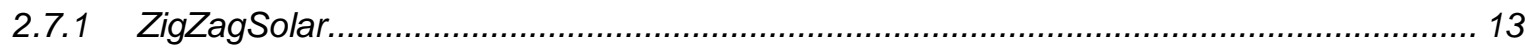

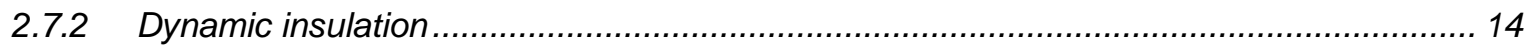

2.7.3 Semi-transparent Solar Thermal Facade........................................................ 15

2.7.4 Fix louvre-blade shading system with integrated $P V$............................................. 17

2.8 Summary of modelling approaches used in the case studies ......................................... 19

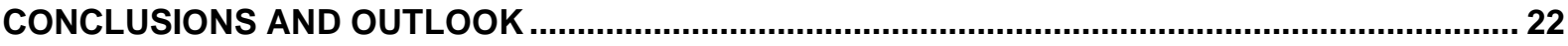

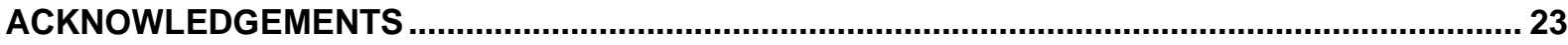

REFERENCES ....................................................................................................................... 24 


\section{Overview}

This report presents a review about simulation models of building integrated solar envelopes. The models can be used to predict the performance of a building integrated solar envelope for a specific case. Such cases include a building, a technical building plant and a location and climate. The performance of a building integrated solar envelope depends on the case. Therefore, it is very important for building projects that the performance of a building integrated solar envelope can be predicted easily and accurately. 


\section{Review of simulation models}

\subsection{Abstract}

Building integrated solar envelopes (BISE) integrate multiple systems in the façade to offer lower energy use, increased indoor comfort and/or enhanced architectural value compared to externally mounted components with similar functions. To support the development and practical application of such envelope systems, there is a need for effective performance prediction and analysis methods. Building performance simulation (BPS) can play a useful role in meeting this demand. However, in practice, there is little guidance for simulation users to find a good match between the features of BISE technologies and the different modelling capabilities of various BPS tools. Here, it is advocated that users should follow approaches such as the fit for purpose framework to ensure their models are useful. With that framework in mind, this article first provides a review of the sub models that can be used for BISE models depending on the characteristics of the technology under consideration. Then, an informed walkthrough of BISE case studies, carried out by expert simulation users is presented, emphasizing how the modelling approaches fit the purpose of the task and why certain sub-models and assumptions were chosen in the given examples. With this, the article offers a basis for researchers and practitioners to choose a model for new BISE technologies that offers the best combination of accuracy, cost, and user-friendliness.

\subsection{Keywords}

Building integrated solar envelopes (BISE); review; building performance simulation (BPS); fit for purpose; solar architecture; building energy performance simulation (BEPS);

\subsection{Nomenclature}

\begin{tabular}{|llll|}
\hline$\alpha$ & Solar absorptance (-) & $\mathrm{h}_{\mathrm{c}}$ & Convection coefficient $\left(\mathrm{W} /\left(\mathrm{m}^{2 *} \mathrm{~K}\right)\right)$ \\
$\alpha(\lambda)$ & Spectral absorptance $(-)$ & $\lambda$ & Thermal conductivity $\left(\mathrm{W} /\left(\mathrm{m}^{*} \mathrm{~K}\right)\right)$ \\
BEPS & Building energy performance simulation & $\mu$ & Dynamic viscosity $\left(\mathrm{Pa}^{*} \mathrm{~s}\right)$ \\
$\mathrm{BIPV}$ & Building integrated photovoltaics & $\mathrm{Nu}$ & Nusselt number \\
$\mathrm{BISS}$ & Building-integrated solar systems & $\mathrm{Pr}$ & Prandtl number= Cp* $\mu / \lambda$ \\
$\mathrm{BIST}$ & Building integrated solar thermal & $\rho$ & Solar reflectance $(-)$ \\
$\mathrm{BPS}$ & Building performance simulation & $\rho(\lambda)$. & Spectral reflectance $(-)$ \\
$\mathrm{Bt}$ & Biot number & $\mathrm{Re}$ & Reynolds number \\
$\mathrm{Cp}$ & Specific heat capacity $\left(\mathrm{J} /\left(\mathrm{kg}^{*} \mathrm{~K}\right)\right)$ & $\mathrm{BISE}$ & Building integrated solar envelope \\
$\varepsilon_{\mathrm{i}}$ & Emittance of the interior surface of the facade $(-)$ & $\mathrm{T}$ & Solar transmittance $(-)$ \\
$\mathrm{g}$ & g value, also known as "solar factor", "solar heat & $\mathrm{T}(\lambda)$ & Spectral transmittance $(-)$ \\
& gain coefficient $($ SHGC)" or "total solar energy & & \\
& transmittance" (-) & & \\
$\mathrm{Gr}$ & Grashof number $(-)$ & $\mathrm{U}$ & Thermal transmittance $\left(\mathrm{W} /\left(\mathrm{m}^{2 *} \mathrm{~K}\right)\right)$ \\
\hline
\end{tabular}

\subsection{Introduction}

Building performance simulation (BPS), is a computational method that can be used to predict the performance of buildings. It allows new ideas for sustainable building design to be explored and tested by simulating external and internal conditions in a building with the goal of replicating real operating conditions and predicting the performance of the building according to chosen targets. During the last decade, the capabilities of BPS tools have substantially improved as they have benefited from continuous development in active communities, gradually incorporating new modelling possibilities, options, and added features [1-4]. As a result, BPS has increasingly positioned itself as a foundation in advanced building consulting for design and operation [5] and a mean of addressing climate change related issues [6]. Furthermore, it has shown value for supporting renewable energy integration $[7,8]$ and providing help to make informed decisions for complex buildings with advanced technological systems [9-11]. In the push for creating a more sustainable and energy efficient built-environment, BPS tools can play a major role improving the design, construction, and operation, and of new and existing buildings [12]. However, this requires simulation user to have access to not only increasingly flexible models which can adapt to new scenarios, but also to guidance 
allowing them to pick the right models to successfully predict the performance and added-value of such integrated technologies.

Building integrated solar envelopes or BISE, are a particularly interesting example of advanced facade systems. According to the authors in [13], BISE are building envelopes that use solar irradiance to provide one function to the building in addition to fulfilling at least one other role in the building envelope. In other words, an BISE is an integrated system that provides the possibility to convert or harvest energy from the sun by means of absorption or transmission in addition to fulfilling at least one traditional facade requirement such as mechanical stability, fire safety, provision of a healthy environment and noise protection [14]. Typically, the strategy is to integrate a technology that will positively impact the buildings' energy demand and/or improve user comfort [13,15-18]. Examples of BISEs could be innovative daylighting and solar control systems, building-integrated solar thermal (BIST) collectors, building-integrated photovoltaics (BIPV), or technical building services (i.e. ventilation systems or heat pumps) integrated into the building envelope. More BISE examples are provided in $[19,20]$.

Integrating systems for renewable energy harvesting in facades, is also interesting as it not only may sometimes increase the building's architectural value [21], but from an economic standpoint, has already proven to provide savings on investment costs compared to the equivalent non-integrated systems [13].

Although some BISE systems have successfully managed to penetrate the market, others still face barriers preventing them to reach their full commercial potential $[22,23]$. This is for the most part due to the lack of knowledge surrounding their possible advantages, and is typically cost related [24]. In practice, if the benefits of a technology cannot easily be quantified, the BISE system may fail to penetrate the market even if its returns largely outweigh its costs.

The challenge lies in that BISEs, to a much more complex degree than for conventional building facades, embody multiple interdependent physical domains with transient energy flows which BPS tools are not originally engineered to support. Hence, the issue is that they typically need one or multiple interconnected sub-models that must sufficiently describe their thermal, optical, airflow, and electrical parameters [3] and must be able to compute these models simultaneously in a way that allows them to exchange information during the simulation process. This specificity introduces a lot of difficulties for simulation tools which come short of providing the flexibility to simulate changing properties such as variable the thermal transmittance of the envelope [25]. Other issues may relate to the capacity to implement dynamic control strategies in response to the influence of shading from neighbouring buildings [26], self-shading of the system [27], demand-side characteristics (heating/cooling/electricity), and building plant components among others. The difficulty of choosing the right modelling approach, which will accurately capture the desired properties of the technologies for the given context, is compounded by the fact that there can be a plethora of models available for the same technology. As reported in $[28,29]$ in the case of semi-transparent BIST systems, the methods may vary from using detailed physical models [30] to using much simpler ones [31]. Ease-of-use, computational requirements, input need, output options, physical domains considered, necessary domain knowledge, etc. are elements that will require different levels of detail in the choice of the final modelling approach.

Overall, finding the appropriate modelling approach, deciding on a simulation environment, and making the best possible use of the available resources, can be a challenging task. The "fit for purpose" framework [32,33] is a modelling approach which encourages considering what the problem needs instead of starting from what a specific simulation tool can offer. Thereby it promotes intelligent use of models, and informed decision-making processes that take into account the fitness of the model to abstract a real system. Ultimately, the aim of this procedure is to help select cost-effective strategies by reducing the risk of picking the "wrong" model, i.e. a modelling approach that is too simple/too complicated and could lead to inaccurate results, high uncertainty or overly costly simulations.

In order to apply the fit for purpose framework to BISE and help users make well-considered decisions about appropriate complexity levels of their simulations, it is essential to have an in-depth understanding of the basis and assumptions of the various available sub-models implemented. Unfortunately, in the context of BISEs and to the knowledge of the authors, there is little guidance available to simulation users that could help them choose adequate modelling approaches. Additionally, because of the multidisciplinary aspects of BISE, simulation users may have very different backgrounds (for instance architecture, structural engineering, building physics, electrical engineering, automation) which complicates the task of providing such multidisciplinary guidance. 
The purpose of this article is to attempt to start bridging this gap by providing information about the most common explicit physical models used for BISE performance prediction as well as highlight their main assumptions and applications. In order to do that, this article first provides a review of the sub-models which can be used for BISE models depending on the characteristics of the technology modelled. Then, an informed walkthrough of BISE case studies carried out by expert simulation users is proposed, emphasizing how the modelling approaches followed fit the purpose of the task and why certain sub-models and assumptions were chosen in the given examples. With this, the article offers a basis for modelers of new BISE technologies to choose a model that offers the best combination of accuracy, cost-efficiency and user-friendliness.

The scope of this review is limited to BPS tools aimed at predicting BISE performance in terms of energy and environment, and therefore does not encompass other BPS models that could be used e.g. for structural engineering, fire safety, or acoustic evaluations. Furthermore, the intended target audience, referred to as simulation users in this article, consists of researchers, industry professionals, and graduate students.

\subsection{Framework for choosing BISE modelling approaches}

This article uses the fit for purpose framework as a backbone, as illustrated in Figure 2, and accordingly relies on two complementary sections to provide simulation users with both background information (section 2.6) and practical examples (section 2.7) to help them decide on a BISE modelling approach to follow. This choice should follow a careful analysis of the available information, awareness of important limitations of the methods, and an open mind to alternative approaches which best serve the purpose of the simulation. Due to scope limitations, this review is not able to cover the entire fit for purpose framework applied to BISE modelling as it does not cover the specific capabilities of the different BPS tools available, and instead the focuses on energy-related topics in buildings. Section 2.6 aims at providing simulation users with an overview of the most common BISE modelling approaches based on explicit physical parameters, and which are used in BPS to characterize thermal, optical and electrical aspects of BISE systems. The details of section 2.6 are presented in Figure 1.
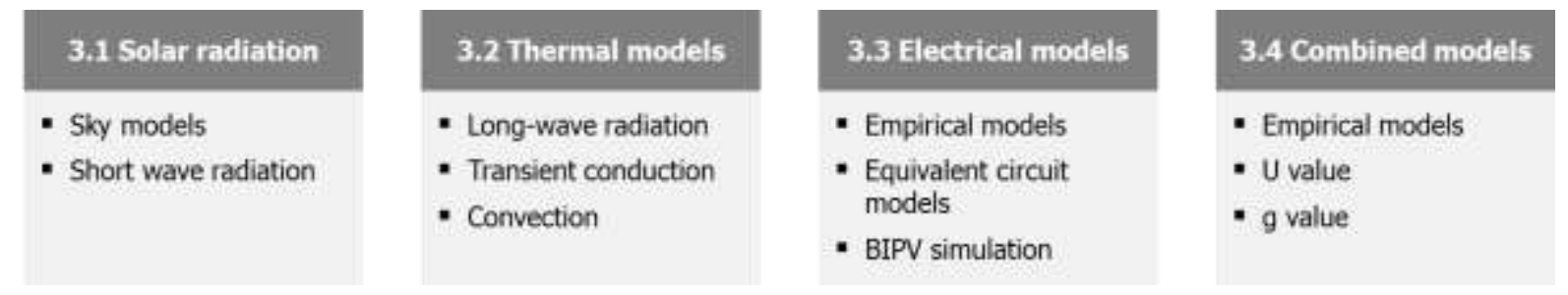

Figure 1. Overview of the model classification used in section 2.6.

The different types of models or sub-models are listed by physical domains, from the most detailed to the most simplified approach. Detailed models make the least assumptions and require the most input from the simulation user; while simplified models do not describe explicitly all the physical parameters which means they rely on a larger number of assumptions. Despite the latter possibly having limited scopes, they are useful when there is either no need for a detailed description of the physical phenomena, or when information about the necessary model parameters is too uncertain or void. Since BISEs have particular characteristics that separate them from traditional facades, section 2.7 of this review focuses on providing detailed examples of how different issues were solved in previous studies carried out by some of the authors, whom have many years' experience with building simulation. For each case study, the justifications for the assumptions made and possible simplifications are provided, along with insight on challenges and difficulties that may have been experienced. The goal of section 2.7 is to share know-how and help the simulation user understand how the previously described models can be combined to provide successful simulations by following the recommended thought-process shown in this article. 


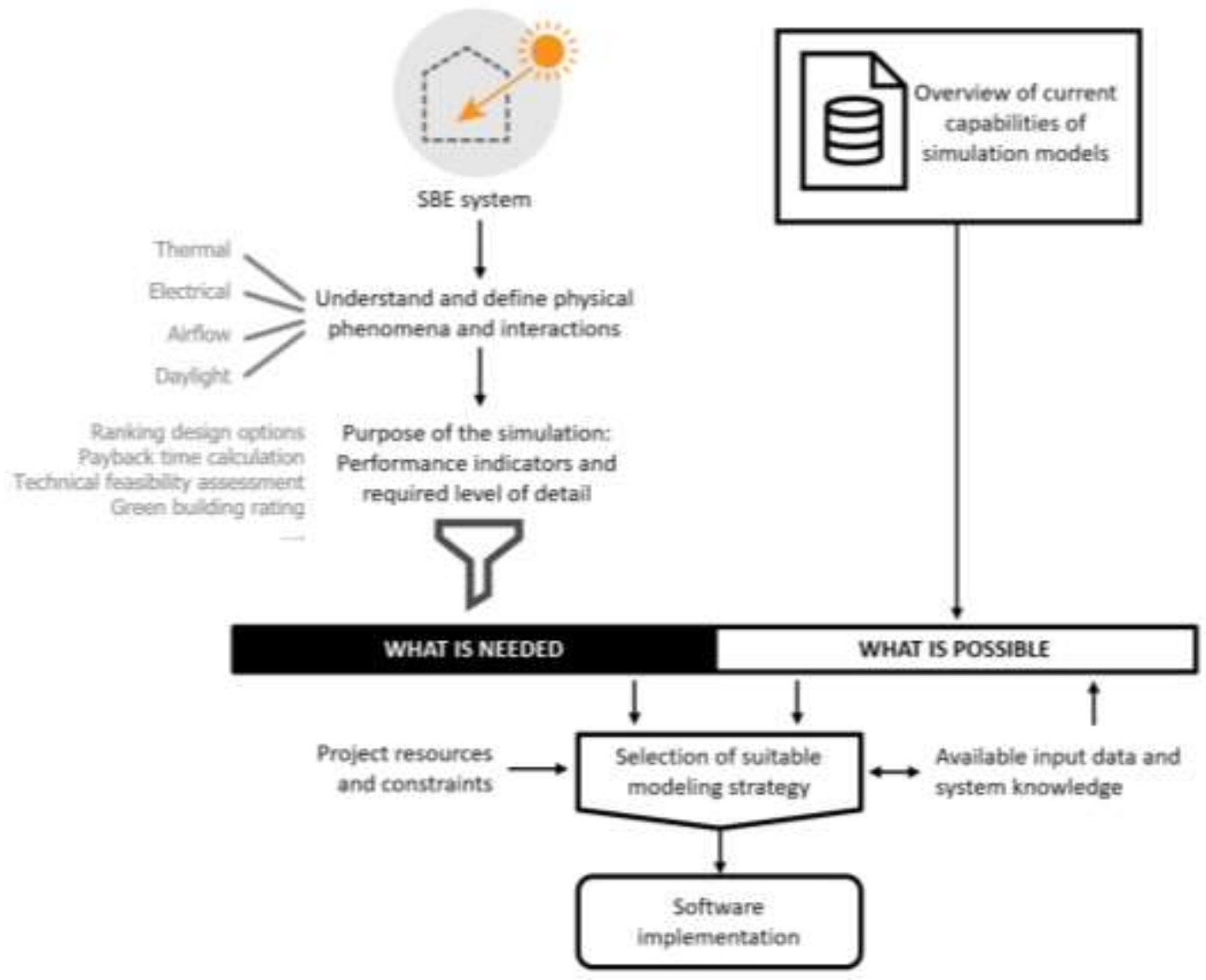

Figure 2. The fit for purpose approach as a framework for predicting the performance of building integrated solar envelopes using BPS.

\subsection{Modelling approaches for building integrated solar envelopes}

\subsubsection{Models for solar radiation}

Selecting a model for solar radiation is the essential starting point in the context of BISEs, as the method chosen may greatly influence the outcomes of the simulation. Additionally, depending on the technology modelled, different types of solar radiation data (hemispherical, direct or diffuse radiation, albedo radiation etc.) and different spatial resolutions as well as time-steps (monthly, daily, hourly sub-hourly) may be required. Descriptions of the different types of solar radiation data, their required resolutions and the resulting uncertainty of the models for several renewable energy systems are described by [34]. Additionally, a detailed overview of different methods to calculate irradiance on inclined surfaces is provided by [35] together with an experimental evaluation. The following section provides simulation users with information about the different types of sub-models for solar radiation and their applications, along with references to the bodies of literature for more detailed information on specific topics.

\subsubsection{Sky models}

In BPS, the sky is generally modelled by discretizing it into smaller patches of solid angles. Tregenza et al [36] described a discretization of the sky into patches, so that the irradiance on the building integrated solar envelope from each patch can be calculated e.g. according to [37] as presented by [38]. This approach is however one of many, and it possible to use higher levels of discretization than Tregenza sky models as well as to use different approaches to discretize the surroundings $[39,40]$. An overview of methods to calculate the irradiance from each patch is available in [35]. For components with angle-selective properties, it can be important to treat the irradiance from different directions separately. Furthermore, if the performance of a building integrated solar envelope element depends strongly on other characteristics of the solar irradiance, such as spectral properties or polarization, then models for the solar irradiance should provide this information to the optical simulation of the element. A description of the Reference Solar Spectral Irradiances can be found in the standards ASTM G173-03 and ISO 9845-1. 


\subsubsection{Short wave radiation}

The visible part of the solar spectrum can be described using short wave radiation models, which also include ultraviolet and near-infrared radiation, while the thermal infrared radiation are treated in models for long wave heat exchange and subsequently described in 2.6.2. Short wave radiation models have many applications in BPS and can be used to calculate the solar radiation which is absorbed by the materials of the building, to calculate the demand of artificial lighting or to determine visual comfort levels e.g. regarding the risk of glare. In the context of BISE, short wave radiation models may be particularly useful if the set of optical properties of the system varies over time. This is for example the case if the component includes a movable shading system or is sensitive to shadows being cast on it, in which case the performance must be assessed including all possible scenarios. For transparent components such as windows, shortwave radiation must be taken into account since solar radiation is absorbed and then transmitted into space as longwave radiative and convective heat transfer. The optical properties that are used as input in in short wave radiation simulations are typically: the solar absorptance $\alpha$, the solar transmittance $\mathrm{T}$ and the solar reflectance $\rho$.

\subsection{Detailed models: ray tracing}

A ray tracing simulation considers a light source which emits beams or rays in certain directions. The idea is to follow the path of each ray and calculate the transmitted and the reflected components at each surface the ray encounters. Ray tracing can be performed from light sources like the sun towards the building materials ("forward") or from a certain position, for example a desk, searching possible light sources ("backward").

Raytracing is widely used for modelling radiation through structured surfaces which may have applications such as simulation of light trapping properties in textured optical sheets for photovoltaic energy conversion $[41,42]$.

Radiance [39] is an example of an open source backward ray tracing software, which is often used for daylight simulations. Raytracing is useful for daylighting purposes as it allows calculating illumination on different surfaces in the building, absorbed solar energy, and simulating visual comfort levels including risk of glare [40]. It can be used for glass panes with thin coatings or other spectrally selective layers which are difficult to simulate accurately without taking into account detailed optical properties. Such is the case when the transmittance and reflectance properties of component are anisotropic, meaning they depend on the direction of the irradiance, its wavelength and its polarization. Modelling and simulating complex fenestration components may require multiple separate raytracing simulations in order to be accurate enough to represent the actual behaviour of the system. On the other hand, when the model is of non-scattering and homogenous material, the solar transmission can be calculated analytically without using ray-tracing techniques and if the optical properties do not change significantly depending on the angles, some samples can be treated as if they had spatially averaged "effective" solar properties and may not require raytracing techniques either [43].

\subsection{Detailed intermediate models: bidirectional scattering distribution function}

Bidirectional scattering distribution functions (BSDF) are used to calculate solar heat gains in fenestration assemblies with layers made of non-specular materials - meaning they scatter radiation in many directions- such as windows with shading systems. The methodology defined by $[44,45]$ is often used to discretize the possible directions of scattering, based on the properties of each layer. However, other discretization may be necessary depending on the properties of the system.

\subsection{Detailed intermediate models: the four-flux model}

The four-flux method assumes that the total flux traversing a component is decomposable into two collimated or direct fluxes traveling perpendicular to the component layer in the forward and backward directions, and two diffuse fluxes traveling in the forward and backwards direction. The collimated fluxes decay due to absorption and scattering in the layers. Additionally, the forward travelling diffuse flux loses intensity due to absorption and scattering in the layers, and grows due to scattering of the backward traveling diffuse flux, forward scattering of the forward traveling collimated flux, and backscattering of the backward traveling collimated flux. The same process happens with the backwards traveling diffuse flux. If a BISE can be considered to consist of several optical layers that transmit and reflect parallel direct radiation and isotropic diffuse radiation, then the "four-flux model" described in $[46,47]$ can be used. As illustrated in Figure 3, it uses one channel for the direct radiation and one for the diffuse radiation, allowing scattering from the direct channel into the diffuse one. It makes spectrally resolved simulations easier, but can also be used with integral optical values, angle-dependent values and even polarization-dependent values. 


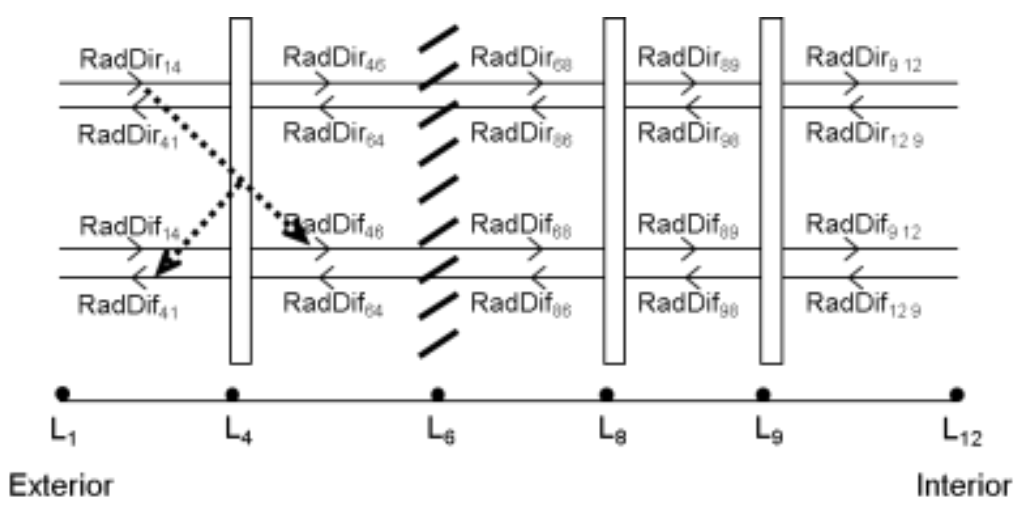

Figure 3. Schematic diagram of a four-flux model with four active layers. The dotted arrows mark a direct-diffuse transmission and reflexion of layer L4. [63].

\subsection{Simple intermediate models}

Simplified models for ray tracing and the four-flux method can both be used to calculate the effective absorptance depending on the direction of the irradiance for each layer of the BISE as well as the effective transmittance of the entire BISE depending on the direction of the irradiance. Effective means in this case that the effect of multiple reflections is included. The solar energy absorbed in each layer can then be calculated in each time step of the simulation by the sum of the products of the irradiance from a certain direction and the effective absorptance for this direction, which is much faster than solving the four-flux model in each time step. Empiric models such as the one proposed in [48] can be used to fit problems with angle-dependent of optical properties. Alternatively, an analytical solution to the four-flux method is presented in [49] based on a transfer matrix and allows to solve problems with limited numbers of layers.

\subsection{Simple models}

The simplest way to model the optical properties of an BISE is to use a single value representing the fraction of solar energy which is absorbed in the building. A slightly more detailed approach is to separate between the average transmittance of the BISE, and the average absorptance of the building interior or differentiate between the different orientations of the BISE component. In this case the average absorption can then be calculated more accurately if using specific absorptance values for the materials of the walls, floor, and ceiling. Further, instead of distributing the transmitted irradiance evenly on all surfaces of the interior, it is possible to use time series representing the distribution, although this method may prove difficult without ray-tracing simulations. When dealing with multiple parallel non-spectrally selective layers, the easiest calculation method is to use a single incidence angle with single integral values for the transmittance and reflectance of each layer. This can be handled analytically using the equations of EN 410 [50]. As the angle of incidence of solar rays on a building changes considerably throughout a day, different angles of incidence can be considered for more accuracy. If the optical layers do not have an incidence angle symmetry as it is for example typical for venetian blinds, then optical simulations can be performed for different solar altitude angle and azimuth angles relative to the orientation of the envelope element. For BISE technologies with performance profiles that are highly sensitive to solar incidence angle, such as BIST or BIPVT systems, one can use the incident angle modifier method. This model implements several equations which can be used to approximate the angle-dependency of the performance [51-53].

\subsubsection{Thermal models}

The description of the thermal behaviour of a building integrated solar envelope is achieved using mathematical equations that translate the thermodynamic behaviour of the building. In an BISE, thermal models describe heat transfer inside a material or component and with the surroundings by means of conduction, convection, and radiation. Such a model is typically implemented when the considered component is associated to a function (or possesses properties) requiring a detailed description of temperature fields or heat flow. Transient models are dynamic models which account for energy storage effect under transient boundary conditions. Heat transfer is calculated one time-step after another with intervals which depend on the goal of the model. In order to be able to use advanced thermal models, the material properties need to be specified in thermal models: thermal conductivity $\lambda(\mathrm{W} / \mathrm{mK})$, density $\rho(\mathrm{kg} / \mathrm{m} 3)$, sensible and latent heat capacity or thermal capacity $\mathrm{Cp}(\mathrm{J} / \mathrm{K})$, the infrared emissivity $\varepsilon$, as well as properties of fluids such as the thermal expansion coefficient and the dynamic viscosity $\mu$, which together with other properties allow to determine the dimensionless numbers used in fluid dynamics in the context of heat transfer within fluids. 


\subsubsection{Long-wave radiative heat transfer}

In any material with a temperature above absolute zero (0 Kelvin), moving charged particles of the atomic structure are responsible for the emission of electromagnetic radiation through the material's surface. In the context of building envelopes, it is useful to describe heat transfer between two or more surfaces. The two main physical parameters used to compute long-wave radiation of a given material surface are: the infrared absorptance and emittance. The thermal energy emitted by a surface is highly sensitive to its temperature, and also varies according to the amount of radiation absorbed and reflected by the surface. It may also depend on the wavelength (spectral dependency), and in models with increased complexity, on the angle of incidence of the radiation (angular dependency) and on the phase of the electromagnetic radiation.

The long wave heat exchange received by an external surface is the difference in between the emitted and received flux. The surroundings of the surface are characterized by and equivalent temperature which is a function of the sky temperature [54], ground temperature and surrounding temperature as well as the view factors to each of those. Additionally, it is possible to make assumptions which can often simplify the problem. For example, each surface can be considered opaque, diffuse, isothermal and have uniform emission, or be considered grey with wavelength independent properties. The view factors for the ground and the sky, if they are unknown, can be set to default values and finally, the ground temperature can be assumed to be identical to the air temperature or modelled using the sol air-concept [55].

The calculation of longwave radiation between internal surfaces is a combination of emission and multiple reflections between said surfaces, until it is eventually re-absorbed and redistributed [56]. The solution is then a recursive process starting by calculating the emitted flux by each surface and the reflected flux between the surfaces until it is insignificant. Clarke [56] highlights that for most conventional building materials with emissivity, the solutions should be determined after three recursive steps. However, the process will be noticeably longer for materials with low emissivity.

The calculations in the recursive process require the temperatures of the surfaces, their emissivity, the extent to which they are visible to each other (view factor) and the nature of the surface reflections (diffuse, specular or mixed). The geometric view factor is a calculation to determine the fraction of the radiative flux that leaves a surface and reaches another. Various methods to calculate view factors are also described by Clarke in [56].

\subsubsection{Transient conduction in components}

The heat conduction equation model was established by the Joseph Fourier Law in 1822. In its original form, it establishes that time rate of conductive heat transfer through a material is proportional to the negative gradient in temperature and area at right angles to the gradient. This equation is often used with the modification of reducing the heat transfer to a one-dimensional, conduction-only problem in BPS tools, and does not account for any moisture or humidity parameters in the construction. It is the accepted approach in the field of building simulation even though in reality, the heat transfer process within a material which is not a homogenous, crystalline solid can be much more complex. The direct use of the effective thermal conductivity (i.e. that takes into consideration all types of heat transfer within the matter and fluid movement) of a material in the Fourier equation, avoids having to take into account the numerous modes of heat transfer within the material such as solid conduction, gaseous conduction, convection within porous materials, and internal radiation (between fibrous insulation strands, and between bounding surfaces separated by porous insulation). Numerical methods are implemented to cope with general equations that in most of the cases don't have an analytical solution and require a numerical solution. Furthermore, they allow for more accurate modelling, more flexibility and can handle problems that are more complex.

\subsection{Finite differences, finite elements or finite volumes}

Methods based on numerical discretization and simultaneous solution techniques offer increased resolution compared to other methods [57]. A finite-volume (or finite-difference) discretization approach to the conservation of energy is employed to represent the opaque and transparent fabric of a building component. This approach does not require the assumption of linearity to calculate heat transmission-thus allowing material properties to vary with temperature and time. As well, it provides flexibility in the choice of simulation time steps (i.e. sub-hourly). The finite volume method (FVM) refers to the small volume surrounding each node point on a mesh. In the finite volume method, volume integrals in a partial differential equation that contain a divergence term are converted to surface integrals, using the divergence theorem. These terms are then evaluated as fluxes at the surfaces of each finite volume. Because the flux entering a given volume is identical to that leaving the adjacent volume, these methods are conservative from an energy point of view. Another advantage of the finite volume method is that it is easily formulated to allow for unstructured meshes. Depending on the level of discretization, each layer in the component 
can be represented by one node or be divided into sub-layers each modelled as a node. The heat balance is calculated at each node and expresses the thermal interaction between a node and its neighbours. The resulting equation set links all inter-node heat flows over time and space. A simultaneous solution is performed on the equation set to predict-for a given point in time-the thermal state of each node and the heat flows between nodes. It is then possible to determine at each time and space step the characteristics or state of the material.

There is specialized software available for calculations with a large number of volumes, although simple nodal networks can be solved analytically. For intermediate nodal networks, which have numerical solutions, solver algorithms such as [58] can be used so solve the equation system in order to find the value of the parameters like the temperatures at each node. If the performance of a two-dimensional calculation is accurate enough, elements of a cross-section are used but otherwise a three-dimensional mesh using finite-volumes need to be calculated. The option to simplify the analysis from three to two dimensions and the method of specialized solver algorithms apply also to the other models in this paper.

\subsection{Transfer function method}

The transfer function method is an analytical approach to the solution of ordinary partial differential equations using Zeta transforms. This method is applicable to functions that are linear, periodic with time-invariant parameters [56]. The method used to solve the equations is to transpose a problem which cannot be solved in its original definition space, to a new imaginary space where it can be solved. It is then re-transposed into the initial space, and the solutions are recalculated accordingly. Transfer function methods are built as time series based on coefficients and only use present and past temperatures and flows at the boundaries (surface) of the element to compute the heat transfer. Thereby, they do not compute detailed temperature distributions within the layers of the element. The main assumption that is made is linearity of the function which means that that the properties in each layer of the wall are invariant in time and space within the layer. In theory the number of terms in the time-series is infinite, but in practice it is usually truncated at the $100^{\text {th }}$ term. The coefficients in the transfer functions are computed only once at the beginning of the calculation as a preprocessing step. Transfer functions can be used with a different time base in the time- series than the time step of the simulation.

\subsection{Lumped parameter method}

The lumped parameter approach models the whole component as an equivalent electrical circuit in transient regime and discretizes the system into a number of "lumps", within which the temperature is homogenous.

Using an electrical circuit analogy, every lump in a component is represented by an equivalent thermal resistance and a capacitance, which allows modelling heat storage due to the thermal mass of the material around one node. In this analogy the temperature difference between two nodes is equivalent to the voltage in an electrical circuit, and the heat flux is calculated as the current in the equivalent electrical system. The equations of the equivalent circuit and corresponding solutions are expressed according to the boundary conditions of the physical system (Cauchy conditions two boundary conditions in space and one in time). This method requires calculating one integral and first order derivatives and uses the superposition principle.

This method also presupposes the assumption of linearity e.g. the properties do not change in time or space and there is no spatial variation of the temperature in the lump itself, and only variation in time; which is a noticeable mathematical simplification of the heat transfer calculation. Newton's law of cooling also presupposes that heat conduction through the modelled component is much faster than the heat transfer at its boundaries.

\subsubsection{Convective heat transfer}

Convection is the transport of thermal energy in a fluid (or gas) by the combined effect of heat diffusion and mass (fluid) transfer. It is taken into account on the surfaces of building envelopes but also inside gas-filled cavities (i.e. window cavities, spaces in double skin facades etc.) Convective heat transfer varies according to the type of flow, if it is buoyancy-driven (temperature), wind driven or both.

The most complete set of equations translating the conservation of mass, momentum and energy in a volume is the Navier-Stokes equations. They are primarily used in problems involving turbulent airflows and require advanced numerical methods such as the ones used in computational fluid dynamics (CFD) software to be solved. They call for high computational power to solve the equation at each time step. Because of this, models based on the NavierStokes equations are typically not used in simulation that include transient state and last over a long period of time. However, it is possible to couple simulation environments with CFD software and reuse the information obtained for longer simulation runs.

There are three approaches that can be used to model turbulence within CFD simulation: direct numerical simulation (DNS), Large Eddy Simulation, and Reynolds averaged Navier-Stokes equations (RANS). 
In most BPS tools, and unless using CFD simulations, air velocities for local convection effects are calculated using approximations to reduce the computational power demand and simulation time. Most methods model heat transfer via convection using a convection coefficient $h_{c}$ in $\left[\mathrm{W} / \mathrm{m}^{2} \mathrm{~K}\right]$ which can be determined based on several approaches. Additionally, this coefficient can be corrected using measured values of the flow on a prototype system or by extrapolating values from a similar set up.

As an average for the whole year, [59] defines an external heat transfer coefficient of $25 \mathrm{~W} /\left(\mathrm{m}^{2} \mathrm{~K}\right)$ and an internal heat transfer coefficient based on the emittance of the interior surface of the facade $\varepsilon_{\text {i. }}$ For glass with an emittance of 0.837 , an internal heat transfer coefficient of $7.7 \mathrm{~W} /\left(\mathrm{m}^{2} \mathrm{~K}\right)$ results. Average values are defined by ISO 9050 and separate values for summer and winter are defined in ISO 15099 [60]. The difference between the values is due to the wind usually being stronger in the winter.

CFD simulations are complex and can hardly be performed at each time step of a whole-year simulation. Therefore empiric approaches were developed for the convective heat transfer coefficient between the exterior surface and the ambient air temperature, which include the wind speed [61-65].

\subsection{Convective models based on empirical values from tables}

The most common method is to determine an convective heat transfer coefficient $h_{c}$, calculated using the empirical and dimensionless values of the Reynolds number (Re), the Prandtl number ( $\mathrm{Pr}$ ), the Nusselt number $(\mathrm{Nu})$ and the Grashof number $(\mathrm{Gr})$. These values are dependent on the nature of the flow (natural, forced or mixed), the type of flow (laminar, transitional or turbulent) and the direction of the flow (vertical upwards, vertical downwards, horizontal etc.) and the geometry of the problem (i.e. the length of the surface of heat exchange between solid and fluid).

Equations to calculate convective heat transfer coefficients in different conditions are provided for example by [6668].

Similarly, convection to exterior surfaces is computed using a convection coefficient. The convection coefficients are derived from empirical correlations and linear convection correlations. Convection to the outdoors is complex as it involves buoyancy driven flows around buildings.

When a fluid circuit is used to collect or distribute heat for example from a storage tank to a thermally activated building system, then a hydraulic simulation can be helpful in order to reach an homogeneous flow distribution and to reach a low overall pressure loss. It is based on the pressure drops of pipes and plumbing fittings, which depend typically on the velocity and the density of the fluid and empiric parameters for the different fittings. A numerical simulation is needed to determine the mass flow in each part of a complex fluid circuit and the resulting total pressure drop depending on the total mass flow. Based on this, a pump can be chosen that is able to provide the pressure needed to reach the desired operation points [69].

Special cases are BISE which use air for convective heat transfer. In this case, a reasonable amount of leakage can be tolerated, but needs to be accounted for the thermal model [70].

\subsubsection{Electrical models}

To simulate the electrical output of building skins including photovoltaics, several simulation steps are needed. The basis of each electrical calculation is a numerical model of the electrical properties of the PV devices. These electrical models have to result in the electrical output of the involved PV cells, modules, strings and the complete system under different operating conditions, especially under the time-dependent irradiance and temperature conditions. As PV devices are typically characterized in manufacturer's data sheets by measurements under standard test conditions (STC: temperature $25^{\circ} \mathrm{C}$, irradiance $1000 \mathrm{~W} / \mathrm{m} 2$, spectrum according to [71], normal incidence), models are needed that can generalize the electric behaviour to non-STC operating conditions. In the following, a brief overview over widely used models is given. 


\subsubsection{1 (Combined) Empirical models}

A very basic power model has been introduced by Heydenreich et al. [72]. It contains only three empirical parameters and allows for the calculation of the power output at maximum power point for arbitrary combinations of irradiance and temperature. The three parameters can be extracted from the data sheet, if the output is given for at least three different irradiance levels. This is, however, not always the case and thus the parameter fitting is a crucial step for this model. If the parameters can be determined properly, the model enables especially a good description of the low light behaviour, which is of major importance for BIPV. However, effects like partial shading of a cell or a module are difficult to include, as the mode describes only the power output and no detailed current voltage characteristics.

The Sandia PV Array Performance Model (SAPM) is also an empirical model, but it does not only describe the power but is based on the current-voltage (IV) curve [73]. In addition to the widely-used characteristic points on the IV curve $\left(\left(0, \mathrm{~J}_{\mathrm{sc}}\right),\left(\mathrm{V}_{\mathrm{mpp}}, \mathrm{J}_{\mathrm{mpp}}\right),\left(\mathrm{V}_{\mathrm{oc}}, 0\right)\right)$, SAPM parameterizes the electrical behaviour by using two more points on the IV curve to improve the representation of the shape of the IV curve. The large amount of parameters in the SAPM allows for a good description at various operating conditions but not for a direct insight into the physical properties of a PV system, as the parameters do not necessarily have a physical meaning.

A different empirical approach is followed in the loss factors model (LFM) [74], where five physically significant and independent normalized loss factors are considered. Together with the parameters for irradiance, spectral mismatch and temperature, these five loss factors for $I_{s c}, R_{s}, R_{p}, F F$ and $V_{o c}$ determine the electrical output of the module. As the loss factors have physical meanings, the method allows quick identification of unusual performance patterns and can give insightful information during operation of a BIPV system.

\subsubsection{Equivalent circuit models}

The use of equivalent circuit models is also wide-spread in PV simulation tools. In these models, the electric behaviour of a $\mathrm{PV}$ device is represented by an equivalent circuit consisting of one or more diodes, series and shunt resistance. Thus, the complete IV-curve of a PV device can be modelled, not only characteristic points as in the SAPM or loss factor model described above. The simplest version would be the ideal single diode model with only three parameters: photocurrent $I_{p v}$, saturation current $I_{0}$ and ideality factor a. However, the practical relevance of the ideal single diode model is low, as at least an additional series resistance has to be considered to describe a real device. Therefore, the single diode Rs-model, also known as 4-parameter model, has been introduced [75]. Adding also a parallel shunt resistance leads to the single diode Rp-model, also known as five parameter model (e.g. [76]). All single diode models inherently neglect the recombination losses in the depletion region. These can be included by extending the equivalent circuit by an additional diode leading to the two-diode model with two additional parameters: saturation current 102 and ideality factor $\mathrm{a}^{2}$ of the second diode. With these 7 parameters, the two-diode model gets computationally demanding, but also results in a high accuracy especially at low irradiance conditions. For all equivalent circuit models, a precise extraction of the parameters from typically available data sheet information or IV measurements can be challenges and a lot of algorithms have been presented. A good overview about equivalent circuit models and corresponding algorithms can be found in [77]. A comparison of both, empirical models and a diode model, is presented in [78].

\subsubsection{Complete BIPV simulations}

A complete BIPV simulation requires not only an electrical model of the PV, but also prior steps like irradiance calculations (Section 2.6.1), thermal modelling of the PV devices and subsequent steps like DC-AC conversion. Especially the calculation of irradiance can be challenging, as irradiance data of high spatial resolution on each solar cell of the BIPV system are required. As the geometry of the building skin and its surroundings is usually complex, simple view factor methods widely used for simple PV plant configurations cannot be used. Detailed, timeresolved shading analysis is required. There are several tools on the market that partly can fulfil this requirement, mainly 3D CAD programs like for example ArchiCAD, SketchUp, Autodesk Revit or specialized PV simulation tools like for example PVsyst or PV*Sol. A good overview of available tools can be found in [79]. However, all of these tools have certain restrictions and none combines all relevant BIPV simulation steps: detailed irradiance calculation (1), temperature calculations of PV cells (2), electrical DC behaviour (3) and DC-AC conversion (4). In [80], such a detailed model combining all these steps has been presented and validated. Further descriptions, application examples and possible connections to Building Information Modelling of this tool suite can be found in [81]. For the calculation of the time-dependent irradiance on each individual solar cell of a BIPV system, the ray tracing tool RADIANCE is used. For the calculation of the temperature of all PV cells, different models are available [82]. The electrical cell behaviour is described by an equivalent circuit models. Due to accuracy, usually the two-diode model 
is used. Finally, the DC-AC conversion is considered by a parameterized inverter model based on the data sheet specifications of the inverter. Thus, a very detailed simulation of the performance of a BIPV system, especially also for complex building geometries, customized BIPV modules and complex electric circuit designs, can be performed.

The simplest complete BIPV simulation is to estimate the irradiance on the BIPV per year and to multiply it with the average efficiency and an additional factor which accounts for the losses e.g. of partial shading.

\subsubsection{Combined models}

Combined models are models allowing to describe multiple physical domains simultaneously. They are typically less explicit than domain specific models but can in cases where the simulation output does not need detailed output on all parameters, be simpler to use. They include equations for all relevant physical properties, from optical to electric to thermal calculations. They are therefore also called "multi-physic" models. Detailed models can combine multiple models of which the sub-parts may vary in terms of complexity. This is typically not an issue as long as the simplifications used do not significantly change the results.

\subsubsection{Combined empiric models}

Many components of a technical building plant could theoretically be integrated into BISEs. For some technologies, this may be beneficial for example because of increased prefabrication and less disturbance of the people within the building in retrofitting projects.

The variables of one component are often connected to each other. For example, a pump can reach its maximum pressure increase when there is no mass flow and its maximum mass flow when there is no pressure difference. Therefore, equations are often used in order to approximate the dependency of one variable on another one. Such curves can also be used to dimension the technical building plant. Since many variables depend on more than one variable, multidimensional equations are also being used, such as the pressure increase of a pump depending on the mass flow and of the operation mode of the pump.

If the pump is part of a heat pump which is integrated into the building envelope, a detailed model is used for this heat pump. A simpler approach is uses the Coefficient of Performance (COP) of a heat pump which is the ratio of the delivered heat and the needed electricity. If this is measured for several temperatures of the heat source and of the heat sink, the COP can be interpolated during dynamic simulations between those values and the electricity demand can be calculated depending on heat demand at that time.

In some cases, models for technical building plant need to be adapted for building-integrated solutions. If for example a solar thermal collector is integrated into the building envelope, it can be analysed if models which are used for not integrated solar thermal collectors can be used to model the building integrated ones.

The standard model for solar thermal collectors [83] does not involve the temperature or the heat flux towards the building interior. Therefore it turned out not to be accurate even if it is slightly improved [84]. More research finally led to new equations [31], which are based on the standard model and its parameters, but modify them in order to approximate the true solar thermal performance as well as the true heat flux through this BISE.

\subsubsection{U values}

The thermal transmittance of an BISE characterized by a $U$ value $\left(\mathrm{W} / \mathrm{m}^{2} \mathrm{~K}\right)$ includes the heat transfer from the exterior to the surface of the BISE, through the BISE and from the interior surface of the BISE to the interior. It is determined experimentally for defined, static conditions and combines conduction, convection and radiative heat transfer and can be considered as an effective conductance between the ambient temperature and the room temperature. The concept of the $U$ value is implemented in many simulation tools by extrapolation, despite it being valid only for specific conditions, possibly leading may lead to errors in heat transfer calculations. Additionally, it is important to note that $U$ values do not account for thermal capacities and if those have a significant effect on the system modelled, the BISE model should include a thermal network which will account for them.

\subsubsection{3 g values}

In order to add the effects of solar irradiance to mere $U$ value calculations for non-opaque components, the $g$ value also known as "solar factor", "solar heat gain coefficient (SHGC)" or "total solar energy transmittance" was introduced. It quantifies the fraction of irradiance reaching the interior as a combination of the optical solar transmission and the fraction of absorbed irradiance flowing to the interior of the building and is, just like the $U$ - 
value, determined experimentally. Furthermore, the $g$ value is often angle-dependent and is often simplified as being constant although it isn't necessarily the case.

When modelling BISEs, different methods can be used to overcome the issue of variable $g$ values and unless the true $g$ values are known for all cases by measurement [85] or by simulation, a simple [86] or detailed model is necessary for an accurate calculation. This may be especially relevant for BISEs which harvest and transform energy building envelope. Such a situation is described in [30] where the study a solar thermal facade collector showed that the $g$ value is not a constant, and in cases where energy is extracted from - or supplied to - the BISE on top of the optical and thermal exchange with the ambient and the interior.

Simpler models consist in simplifying the $g$ value (for example in the case of a glazing with venetian blinds for a certain location, orientation and control) and calculate an effective $g$ value for which the $g$ values of each time step are weighted by the irradiance at this time step $[43,87]$. In other cases, a variable $g$ value can be implemented using a black-box model such as was done in [88] where separate $g$ values were determined for different directions of the irradiance and different positions of venetian blinds.

\subsection{BISE modelling in case studies}

Keeping the overview of modelling strategies of Section 3 in mind, this Section presents four examples of how modelling and simulation has been used to address specific questions in the research and development process of BISE systems. The objective of these case studies is to illustrate how appropriate modelling methods can be matched to BISE characteristics and specific needs in different project phases.

\subsubsection{ZigZagSolar}

BISE description:

ZigZagSolar (Figure 4) is an energy harvesting façade system that uses reflectors to increase the amount of irradiance that reaches the upwards tilted building-integrated PV modules [89]. From street level, only the reflectors are visible. This gives much flexibility for architectural design optimization of PV modules in vertical facades.

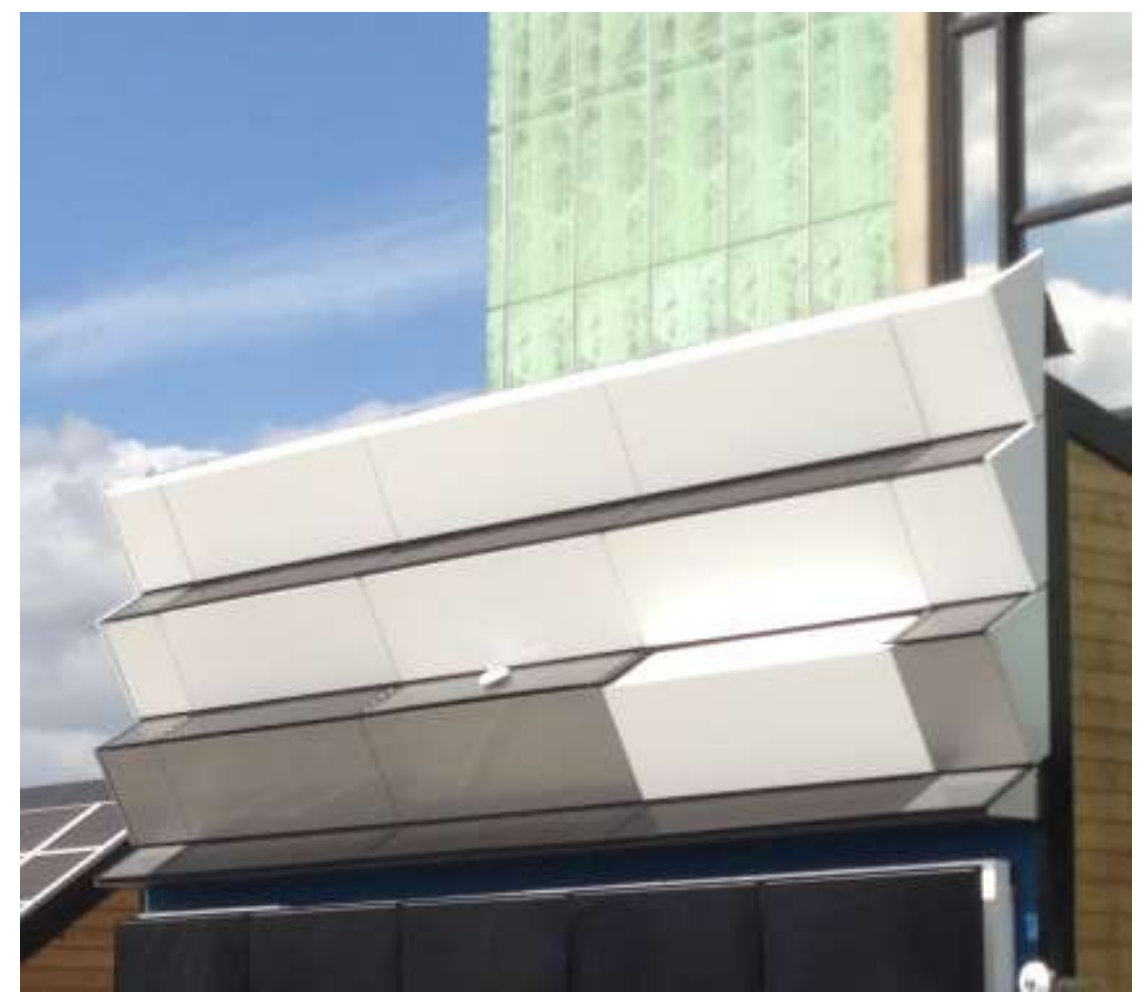

Figure 4. Close-up of full-scale ZigZagSolar demonstrator at SolarBEAT test site, Eindhoven, The Netherlands. 
Purpose of the simulation:

To quantify the amount of electric energy that is produced by the façade system for different climates and façade orientations. The ZigZagSolar façade system is customizable, and therefore it is of interest to investigate which combinations of reflector and collector angles maximize the performance for different situations.

Modelling requirements:

Detailed treatment of solar irradiance is necessary for accurate predictions of the performance ZigZagSolar façades. Three different ways in which irradiance reaches the PV modules need to be included in the model: (i) beam irradiance (direct sunlight) including the effect of (partial) self-shading from other modules, (ii) diffuse irradiance, considering correct treatment of hemisphere shielding because the PV modules only see a part of the sky dome, and (iii) reflected radiation from the reflectors onto the PV modules. Especially this third aspect represents a difference with respect to modelling and simulation of common BIPV systems, as it should include multiple bounces of both specular and diffuse reflectance [90]. A three-dimensional model that respects the geometry of the system and takes the occurring non-uniform irradiance distribution into account is necessary to predict the salient features of this BISE technology [91].

Simulation strategy:

To satisfy the abovementioned requirements, a dynamic ray-tracing-based simulation model was developed using the software Daysim [92]. The approach was inspired by the work presented in [93]. Inhomogeneity of solar irradiance plays an important role in determining the performance of ZigZagSolar. A 2D grid of irradiance sensor points (distance $5 \times 5 \mathrm{~cm}$ ) was therefore modeled in the plane of the receiver. It was found that both average irradiance and irradiance at the mid-point of the receiver are not suitable as performance indicator, because these metrics do not capture the inhomogeneous irradiance effect. In the post-processing phase, the lowest light assumption approach was used to evaluate the performance of ZigZagSolar. This approach assumes that the grid point that receives the lowest irradiance values determines the electrical output of the corresponding module. Based on this approach, it could be identified that an electrical configuration with two parallel strings (i.e. one upper row and one lower row) would be able to mitigate the impact of partial self-shading and can significantly increase the electrical yield of the ZigZagSolar facade system.

Main finding:

It was found that the method of average illuminance is too simple for this case and that ray-tracing is necessary to capture the complexities of combined reflector-collector systems such as ZigZagSolar. A split-pane configuration with two parallel PV strings can boost the performance of ZigZagSolar. The results from the study further showed that more modules can be packed per $\mathrm{m}^{2}$ of façade surface, because in using this split pane approach, partialshading reduces the PV performance less. This effect could not have been observed if a too simple model would have been used.

\subsubsection{Dynamic insulation}

\section{BISE description:}

Active Insulation (Figure 5) is an air-based, closed-loop dynamic insulation system (Figure [94]). When the interior fans are switched off, the system acts as a passive insulation layer. When the fans are switched on, the thermal insulation gets short-circuited, thereby promoting heat transfer between inside and outside. This mechanism can be used to reduce indoor overheating through pre-cooling in summer nights. On sunny winter days, the system acts as heat exchanger, bringing in solar thermal energy from outside to inside

Purpose of the simulation:

To quantify the energy and comfort performance of this innovative BISE, and to identify directions for improvement from whole-building perspective. 
Modelling requirements.

To be able to obtain a realistic representation of the Active Insulation system, there is a need to model controllable dynamic thermo-physical properties of the building envelope. Thermal storage effects inside the slab need to be taken into account in an appropriate way [95]. Flexibility in user-defined control strategies is a very useful feature, and there is a need to evaluate thermal comfort conditions at the whole building level.

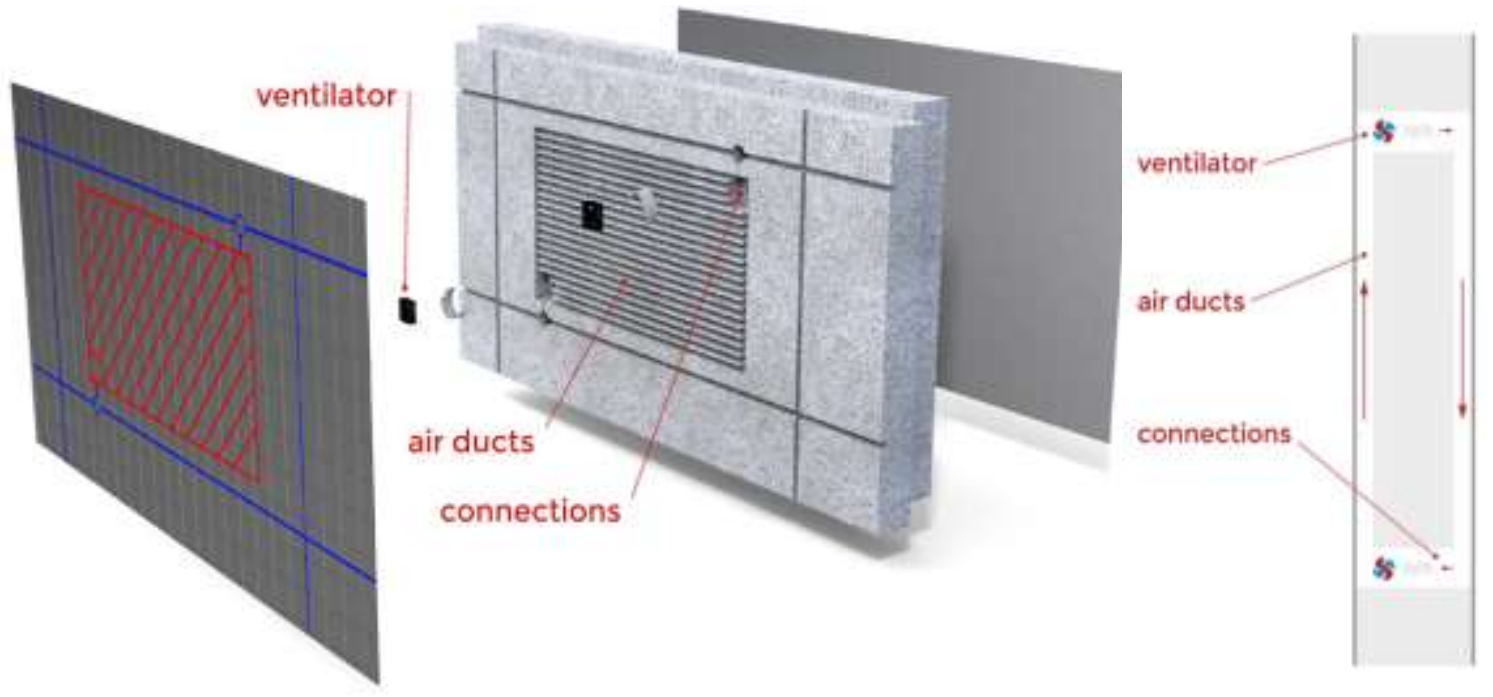

Figure 5. Schematic working principle of Active Insulation.

\section{Simulation strategy:}

In most software tools, it is very challenging to model the performance of this system. Especially, in programs that use the conduction transfer function method, this is not possible according to the requirements presented above. EnergyPlus does, however, does appear to offer some options, including the features: "Movable Insulation Actuator" and "Surface Construction State Actuator" [3]. Coupling to the so-called Energy Management System (EMS) in EnergyPlus is necessary to achieve flexibility in façade control strategies. The Movable Insulation Actuator only works with schedules; not with other user-configurable control strategies or EMS and does therefore not meet the requirements. SurfaceConstructionStateActuator can only work if the assigned constructions (in the state with low and high thermal resistance) have similar thermal storage capacities, otherwise it leads to errors in the nodal placement scheme of the transient conduction model. This model therefore lacks flexibility to test different configurations and is therefore also not suited in the present case. An alternative was found, by modelling Active Insulation as an adapted version of the Ventilated Slab model in EnergyPlus [96]. Using this approach, the air transport, and the heat transfer that ensues from it, is effectively modelled within the building envelope. Comparisons with simulations using the ISO 8990 hot-box method approach indeed show the capability of this adapted Ventilated Slab model to predict the adaptable thermal insulation behaviour of Active Insulation.

Main finding:

Simulation results show that using a dynamic U-value approach (i.e. neglecting thermal mass in the construction) would not resemble the physical behaviour of this BISE at the desired level of accuracy. Using an adapted version of the Ventilated Slab model in EnergyPlus it is possible to predict the performance of Active Insulation according to the modelling requirements

\subsubsection{Semi-transparent Solar Thermal Facade}

\section{BISE description:}

Fully glazed facades of high-rise buildings often lead to large solar gains. Semitransparent solar thermal facade collectors provide visual contact to the exterior as well as solar control and renewable heat [97]. Compared to a triple glazing without shading system, a semitransparent absorber is needed in addition as presented in Figure 6. 
Purpose of the simulation:

To quantify the annual energy savings of a high-rise building equipped with this new technology.

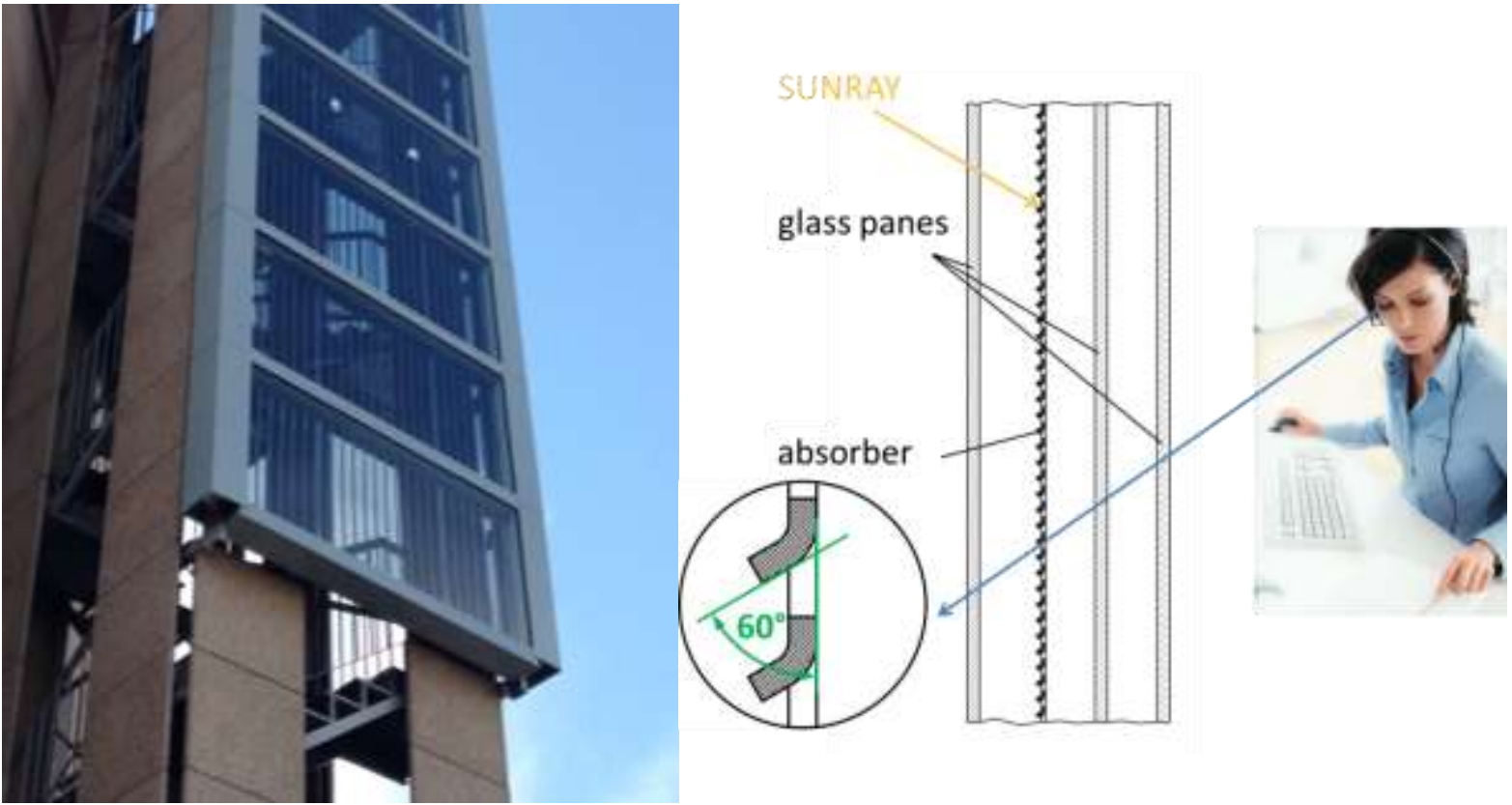

Figure 6. Photo of a demonstration installation at ZAG in Slovenia (left, [16]) and a schematic drawing of the technology.

Modelling requirements:

The solar transmission of the semi-transparent absorber depends on the direction of the irradiance. Therefore not only the direct irradiance was treated in detail in [30], but also the diffuse irradiance was treated separately for 235 different directions. The effective solar absorptance of each layer (exterior glass pane, semi-transparent absorber, centre glass pane, interior glass pane) and the solar transmittance of the whole solar thermal facade was calculated based on angle-dependent and spectrally resolved measurements of the transmittance and reflectance of the individual layers. The spectral resolution was chosen because the different layers have different spectral behaviour. The four-flux model was chosen because spectrally resolved photo goniometer measurements together ray tracing simulations would have been much more expensive. Ray tracing could better account for radiation which is reflected specular by the slats of the absorber. However, the reflectance is only about 0.05 and the transmittance of the exterior glass pane is high. Therefore, the improvement by ray tracing would be very small compared to the necessary effort.

The thermal model used fixed external and internal heat transfer coefficients according to EN 410 [59], but a detailed physical model with separate calculation of the infrared heat exchange and the convective heat exchange. The latter was simulated by CFD simulations for many cases and the entire model was validated by calorimetric measurements of a facade collector sample [98].

\section{Simulation strategy:}

The model of this solar thermal facade was implemented as a new Type within the TRNSYS simulation environment [99], because it offers a good building model and many validated models to simulate the technical building plant. A way was developed to integrate the model into the building envelope of TRNSYS buildings [30]. The BISE model was programmed in $\mathrm{C}$, so that it can be implemented also in other simulation environments if needed. While the modelling was done by a research institute, the model was then handed over to planner of technical building services of high-rise buildings [100]. The planner then simulated the building together with the technical building plant and the BISE. The strategy was that the simulation model can be detailed, as long as it is easy to use [101].

In order to check if similar BISE can be modelled simpler, but still accurate, a simple model of this special BISE was developed. It uses an angle-dependency according to [53], but an efficiency curve for solar thermal collectors according to [83], although the heat losses of this facade collector also depend on the temperature of the building interior. A constant $U$ value and secondary heat gain factor is used to calculate the heat flux to the building interior, 
although this heat flux also depends on the operation of the collector. One solar transmittance was determined for direct irradiance and diffuse irradiance from the sky and one solar transmittance for irradiance from the ground. This includes that the transmittance from the ground is higher due to the slats in the absorber but neglects the direction of the direct irradiance.

The detailed model was then used in order to generate the parameters of the simple model.

The comparison [102] shows that the simple model provides similar annual sums of the heating and cooling demand and solar thermal performance. However, these values differ significantly at the certain times because of the simplifications of the simple model. The simple model can therefore only be recommended for first approximations and not to plan the technical building plant.

Main finding:

Figure 7 presents three of the four most important results of this BISE model. Compared to a fully glazed facade, the semi-transparent solar thermal facade collector in the spandrel area can provide significant primary energy savings which could even be increased from 7 to $11 \mathrm{kWh}$ per square meter of floor area by improving the design of the first test models [98]. When the building mass is used, then a technical building plant which includes for example $20 \%$ of the south, east and west facade can cover about $20 \%$ of the heating and cooling demand [102].

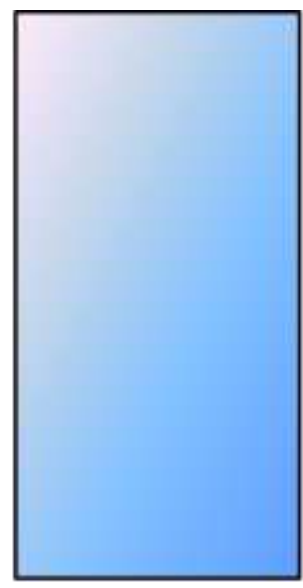

$23 \mathrm{kWh} /\left(\mathrm{m}^{2} \mathrm{a}\right)$
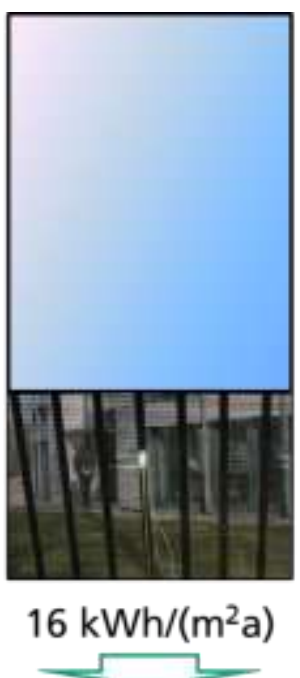

$12 \mathrm{kWh} /\left(\mathrm{m}^{2} \mathrm{a}\right)$

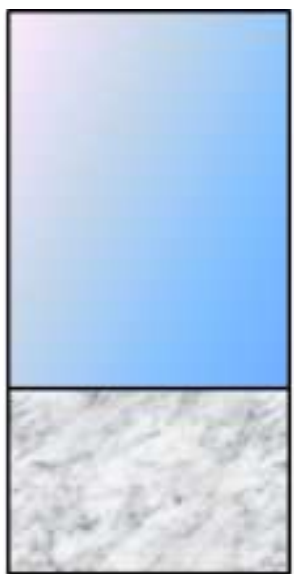

$18 \mathrm{kWh} /\left(\mathrm{m}^{2} \mathrm{a}\right)$

Figure 7. Schematic drawing of the results of the simulation of the primary energy demand of a fully glazed building (left), a glazed facade with semi-transparent solar thermal facade collectors in the spandrel area (centre) and a glazed facade with an opaque spandrel area (right).

\subsubsection{Fix louvre-blade shading system with integrated PV}

BISE description:

The system is a fixed louvre-blade shading device with integrated thin-film photovoltaic on the blades. This system enables the building to manage solar gains while at the same time making use of the "undesirable" part of solar radiation impinging on the shading device. The angle and count of blades is designed to best balance daylight levels in the room, heating and cooling demand as well as solar energy conversion.

Purpose of the simulation:

The aim of the simulation was to develop a methodology using parametric analysis and optimization algorithms to find optimal configurations of fixed shading systems - with regard to blade count and tilt angle - in a Norwegian climate and aimed at balancing competing parameters such as daylight availability, PV conversion and energy demand of the studied space.

Modelling requirements:

The geometry of the louvres, including distribution and tilt angle, is carried out using the algorithmic modelling plugin Grasshopper [103] and is connected to the rest of the building body designed in Rhino v5 [104]. The case study used is the Best-test case 600 as seen in Figure 8. The methodology developed in this study requires that the 
definition of the louvre-blades in Grasshopper be done twice because the optimization process is too computationally intensive to run with same initial definition. The first part of the simulation work is an extensive parametric analysis investigating 52 different configurations and consists in running highly detailed dynamic solar radiation and daylighting simulations using the Radiance based plug-in Diva for Rhino [105] (backwards ray tracing). The second analysis, i.e. the optimization process, is performed with the Hyper-volume reduction algorithm Octopus [106], and uses simplified rtrace (number of ambient bounces) and geometry parameters for the room to keep the simulation run cost-effective. Once the first optimization run is carried out (yielding 200 solutions), the 8 most promising optimized configurations are then re-run with the complete geometry of the room and original rtrace settings. The advantage of developing two different definitions is to be able to perform an optimization with a minimal computation- and simulation timeframe, and then re-run the best performing cases in a more detailed simulation.

a)

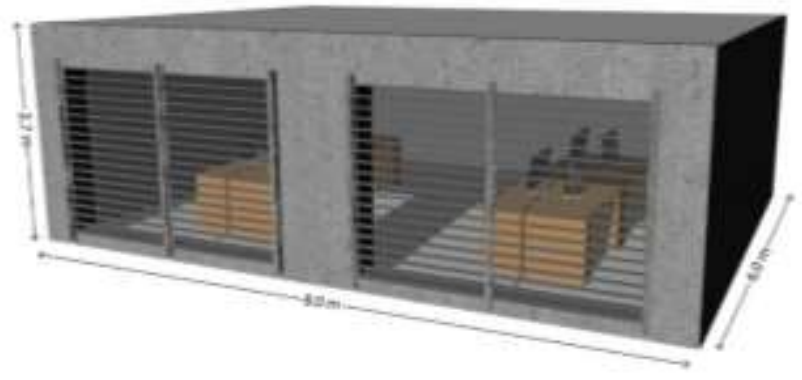

b)

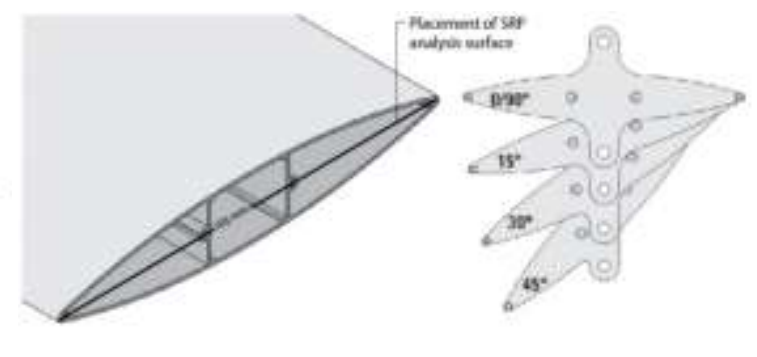

Figure 8. a) The original building geometry from the Best Test case 600 is an $8 \times 6$ meter room with two $3 \times 2$ meter windows facing southwards. b) Louvre-blade geometry and tilt angle illustration.

Simulation strategy:

The strategy followed consisted in finding the most promising configurations of the system through the initial parametric analysis, and then applying an optimization process to further investigate these limited cases. The input used in the parametric analysis were the number of louvre blades in the system (ranging from 10 to 22 blades) and their homogenous tilt angle $(0,15,30$ or 45 degree from the horizontal). The outputs selected for the study were the useful daylight illuminance (UDI), daylight autonomy (DA), continuous daylight autonomy (cDA) and solar radiation potential impinging on the louvre blades (SRP). The optimization process in Octopus is a multi-objective process focusing on maximizing the $\mathrm{CDA}$ and SRP, and hence produces a range of optimized trade-off solutions. Starting from the initial fixed system the optimization allows each louvre-blade up and down the z-axis within calculated ranges that avoid the louvres to overlap. The other parameter for the optimization was individual louvre tilt adjustment. This was done within the same limitations as before, with tilt angles of $0,15,30$ and 45 degrees. The best trade-offs between the objectives produce a set of possible optimum solutions that ideally reach from one extreme to the other. The results from the optimization are presented graphically as a Pareto front, where each cube represents one scenario (Figure 9). Opaque cubes indicate the non-dominated Pareto-front, transparent cubes are dominated solutions that still belong to the Elite. Transparent yellow cubes represent elite solutions from previous generations (history), where the more transparent ones are the earliest results.
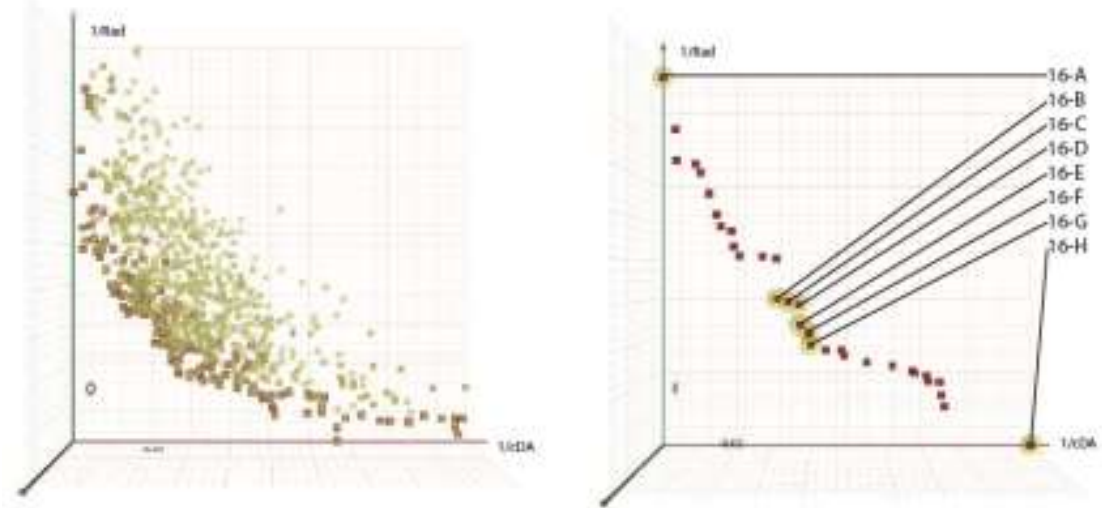

Figure 9. Pareto front analysis for a configuration with 16 louvre-blades (left) and the 8 selected options outlined (right). 


\subsection{Summary of modelling approaches used in the case studies}

Table 1 presents an overview of the four described cases and the levels of detail that were chosen for in the different domains. Apart from the model of the building integrated solar envelope, the simulation environment needs to fit for the purpose, too. There are countless simulation environments and building models which can be used to calculate the energy demand of a building. Some are discussed within [107].

The simplest approach is to assume a constant temperature of the building interior and internal heat transfer coefficient. A building model with five thermal resistances and one thermal capacity is presented by [108]. There are simulation tools with graphical user interfaces (GUI) that make it easy to perform the calculations required by the legislation or to simulate certain technologies and often used technical building plants. There are planning support tools based on spreadsheets such as [109] and very detailed simulation environments, where additional modules can be programmed and added such as [99,110-112]. Some are open source projects like [112], many have their source codes closed and some have a mixture between open source elements and closed source parts. The detailed simulation environments can also offer functions like calculating the thermal comfort or easy coupling with other software such as CFD.

For each simulation environment, a way needs to be developed how to connect the BISE model with the models of the building and of the technical building plant where necessary. For example, [113] developed a way to connect an BISE model to the closed source building model of [99] which can now be used by other BISE models, too. Other approaches were presented by $[114,115]$. Sometimes not even a new BISE model needs to be programmed, but available functions such as zones in the building model can be used to model the BISE [116].

It is also important to check which parts of a simulation are coupled and which can be performed separately, in order to save computing time. This particularly affects the control. A simple control needs only inputs which are available also when the simulation is decoupled into several parts. A detailed control may require inputs which prevent the simulation to be split up into simpler parts. For example, a solar control system can be controlled simply by the irradiance on the system which is easily available in many simulation environments. In this case, the optical simulation can often be decoupled from the thermal building simulation. The optical simulation is then performed only once for each location and orientation and only its results are needed. This saves much time when many thermal building simulations need to be performed. However, if the temperature of the building interior is a necessary input for the control of the solar control, this coupling increases the computational effort.

Sometimes, simpler models as the ones available in one simulation environment can be used for parts of technical building plants. For example for [100], a large part of the technical building plant was not modelled in TRNSYS, but in MATLAB to speed up the simulations. Other forms of co-simulations couple entire detailed simulation environments in order to profit from the best functions of both simulation environments [117-121].

Often, one simulation environment is preferred in the current case while another simulation environment may be required in the next case. For this, the concept of multi-environment models was developed [122] in order to make the same code available in many simulation environments. The code is compiled to machine-code and then linked to a wrapper in the targeted simulation environment. As this is much closer to the hardware than most cosimulations, it can reach the computing times of BISE models that were programmed natively in the preferred programming language of the targeted simulation environments. Therefore, this approach is recommended for BISE companies aiming at cost-effective processes [86]. 
Table 1. Overview of the level of details of the sub models that were used in the case studies.

\begin{tabular}{|c|c|c|c|c|c|c|c|c|}
\hline \multirow[b]{2}{*}{ Case study } & \multirow[b]{2}{*}{$\begin{array}{l}\text { Type } \\
\text { of } \\
\text { BISE } \\
\text { syste } \\
\text { m }\end{array}$} & \multirow[b]{2}{*}{$\begin{array}{l}\text { Purpose of the } \\
\text { simulation }\end{array}$} & \multicolumn{4}{|c|}{$\begin{array}{l}\text { Modelling approach description/ } \\
\text { Detail scale of the simulation }\end{array}$} & \multirow[b]{2}{*}{$\begin{array}{l}\text { Software } \\
\text { used }\end{array}$} & \multirow[b]{2}{*}{$\begin{array}{l}\text { Notes about the } \\
\text { simulation }\end{array}$} \\
\hline & & & $\begin{array}{l}\text { Level } \\
\text { of } \\
\text { detail } \\
\text { for } \\
\text { solar/o } \\
\text { ptical } \\
\text { model }\end{array}$ & $\begin{array}{l}\text { of } \\
\text { detail } \\
\text { for } \\
\text { therm } \\
\text { al } \\
\text { mode } \\
\text { I }\end{array}$ & $\begin{array}{l}\text { of } \\
\text { detail } \\
\text { for } \\
\text { electr } \\
\text { ical } \\
\text { mode } \\
\text { I }\end{array}$ & $\begin{array}{l}\text { of } \\
\text { detail } \\
\text { contr } \\
\text { ol } \\
\text { strate } \\
\text { gy }\end{array}$ & & \\
\hline $\begin{array}{l}\text { ZigZagSola } \\
\text { r }\end{array}$ & BIPV & $\begin{array}{l}\text { Quantifying } \\
\text { the amount of } \\
\text { electric energy } \\
\text { which can be } \\
\text { sold to the grid } \\
\text { depending on } \\
\text { the design of } \\
\text { the facade, its } \\
\text { orientation } \\
\text { and the } \\
\text { climate }\end{array}$ & $* * *$ & NA & * & & Daysim & $\begin{array}{l}\text { Self-shading is an } \\
\text { issue with PV } \\
\text { systems. In this } \\
\text { case, a detailed } \\
\text { model } \\
\text { necessary was } \\
\text { correctly evaluate } \\
\text { the impact of } \\
\text { shading on the } \\
\text { system } \\
\text { performance. }\end{array}$ \\
\hline $\begin{array}{l}\text { Dynamic } \\
\text { insulation }\end{array}$ & $\begin{array}{l}\text { Adva } \\
\text { nced } \\
\text { opaq } \\
\text { ue } \\
\text { wall } \\
\text { comp } \\
\text { onent }\end{array}$ & $\begin{array}{l}\text { To quantify the } \\
\text { energy and } \\
\text { comfort } \\
\text { performance } \\
\text { of this } \\
\text { innovative } \\
\text { BISE, and to } \\
\text { identify } \\
\text { directions for } \\
\text { improvement } \\
\text { from whole- } \\
\text { building } \\
\text { perspective }\end{array}$ & & * & & ** & EnergyPlus & $\begin{array}{l}\text { Control strategies } \\
\text { for components } \\
\text { with variable } \\
\text { thermo-physical } \\
\text { parameters are } \\
\text { not straight- } \\
\text { forward. An } \\
\text { approach with a } \\
\text { variable } U \text { value } \\
\text { was used here but } \\
\text { proven to } \\
\text { insufficiently } \\
\text { detailed } \\
\text { correctly model } \\
\text { the characteristics } \\
\text { of the system. }\end{array}$ \\
\hline $\begin{array}{l}\text { Semi- } \\
\text { transparent } \\
\text { Solar } \\
\text { Thermal } \\
\text { Facade }\end{array}$ & BIST & $\begin{array}{l}\text { To quantify the } \\
\text { annual energy } \\
\text { savings of a } \\
\text { high-rise } \\
\text { buildings } \\
\text { using the } \\
\text { system }\end{array}$ & $\begin{array}{l}\text { * } \\
\text { simplifi } \\
\text { ed } \\
\text { model } \\
\text { *** } \\
\text { detaile } \\
\text { d } \\
\text { model }\end{array}$ & $\begin{array}{l} \\
\text { simpli } \\
\text { fied } \\
\text { mode } \\
\text { I } \\
\text { *** } \\
\text { detail } \\
\text { ed } \\
\text { mode } \\
\text { I }\end{array}$ & NA & $\begin{array}{l}* * \\
\text { both } \\
\text { mode } \\
\text { Is }\end{array}$ & TRNSYS & $\begin{array}{l}\text { The detailed } \\
\text { simulation was } \\
\text { used to check } \\
\text { whether } \\
\text { simplified model } \\
\text { can be used for } \\
\text { future simulations. }\end{array}$ \\
\hline $\begin{array}{l}\text { Fix louvre- } \\
\text { blade } \\
\text { system } \\
\text { with } \\
\text { integrated }\end{array}$ & BIPV & $\begin{array}{l}\text { To develop a } \\
\text { design } \\
\text { methodology } \\
\text { for fix shading }\end{array}$ & $* * *$ & ** & * & NA & $\begin{array}{l}\text { IDA ice, } \\
\text { Rhinoceros } \\
\text { (with plug- } \\
\text { ins } \\
\text { Grasshopp }\end{array}$ & \\
\hline
\end{tabular}




\begin{tabular}{|l|l|l|l|l|l|l|l|l|}
\hline $\begin{array}{l}\text { photovoltai } \\
\text { cs }\end{array}$ & $\begin{array}{l}\text { systems with } \\
\text { integrated PV }\end{array}$ & & & & & $\begin{array}{l}\text { er and } \\
\text { DIVA) }\end{array}$ & \\
\hline
\end{tabular}

* simple model ; ${ }^{* *}$ intermediate model ; ${ }^{* * *}$ advanced model 


\section{Conclusions and outlook}

In order to accurately and efficiently predict the performance of BISE systems, it is crucial that users develop suitable modelling approaches and implement relevant simulation strategies. Thus, they must show careful consideration when matching the purpose of the simulation to its outputs, as well as make sure that the level of resolution of the input required for the model is in line with the information available about the system. Applying the fit for purpose approach in the context of BISE allows users to build on a clear framework and guides them in their choice of submodels with the necessary resolution. With this approach in mind, this paper has provided simulation users with an overview of typical sub-models, relevant for BISE systems, and organized by the physical domain they describe with decreasing level of complexity within it. As the main challenge is to choose the right combination of sub-models, experienced simulation users explained through detailed case studies the modelling approach and the combination of sub-models used to predict the performance of the systems as part of the simulation strategy. The structure of these case studies corresponds to the recommended fit for purpose approach and illustrates how to apply it to BISE systems in practice.

The performance of BISE systems may also further be impacted by occupant behaviour and control strategies, some of which may require smart combinations of existing software. These parameters should also be included in the much broader scope of the fit for purpose approach. Other elements may also be relevant to different categories of simulation users such as cost-effectiveness of the modelling approach or how easily it can be used in earl design phases. Manufacturers could offer models of their BISE to their customers compatible in several simulation environments, because a large variety of simulation environments is used by planners. Models which adapt their accuracy depending on the available input and necessary output could reduce the barrier of switching between different models and software [101]. In the future, experts could provide specific functions as machine-code, which can be detailed and accurate without disclosing confidential details. The machine-code functions of several experts could then be combined to a fast and cost-effective BISE model [122]. In these ways, the modelling of BISE can contribute to reduce the overall costs of BISE and to optimize systems including BISE so that the good BISE technologies can develop to their full economic and ecologic potential.

It is planned to submit this review in an extended version to a scientific journal. 


\section{Acknowledgements}

The authors would like to acknowledge the IEA SHC Task 56, without which this collaboration would not have been possible. The authors thank Tilmann E. Kuhn for fruitful discussions. This work was funded by the Norwegian Research council through the SkinTech project and by the German Federal Ministry for Economic Affairs and Energy (BMWi), based on a decision by the German Bundestag. 
[1] D.B. Crawley, J.W. Hand, M. Kummert, B.T. Griffith, Contrasting the capabilities of building energy performance simulation programs, Build. Environ. 43 (2008) 661-673. doi:10.1016/j.buildenv.2006.10.027.

[2] J.A. Clarke, J.L.M. Hensen, Integrated building performance simulation: Progress, prospects and requirements, Build. Environ. 91 (2015) 294-306. doi:10.1016/j.buildenv.2015.04.002.

[3] R.C.G.M. Loonen, F. Favoino, J.L.M. Hensen, M. Overend, Review of current status, requirements and opportunities for building performance simulation of adaptive facades, J. Build. Perform. Simul. 2 (2017) $205-223$. http://dx.doi.org/10.1080/19401493.2016.1152303\%5Cnhttp://www.tandfonline.com/doi/full/10.1080/19401493.20 16.1152303

[4] M. Milan, Building Energy Simulation and Object-Oriented Modelling: Review and Reflections Upon Achieved Results and Further Developments, Elev. Int. IBPSA Conf. (2009) 638-645.

[5] J. Clarke, A vision for building performance simulation: a position paper prepared on behalf of the IBPSA Board, J. Build. Perform. Simul. 8 (2015) 39-43. doi:10.1080/19401493.2015.1007699.

[6] D.B. Crawley, Estimating the impacts of climate change and urbanization on building performance, J. Build. Perform. Simul. 1 (2008) 91-115. doi:10.1080/19401490802182079.

[7] D. D'Agostino, P. Zangheri, B. Cuniberti, D. Paci, P. Bertoldi, Synthesis Report on the National Plans for NZEBs, JRC Science Hub, 2016. doi:10.2790/659611.

[8] E. Annunziata, M. Frey, F. Rizzi, Towards nearly zero-energy buildings: The state-of-art of national regulations in Europe, Energy. 57 (2013) 125-133. doi:10.1016/j.energy.2012.11.049.

[9] R.C.G.M. Loonen, S. Singaravel, M. Trčka, D. Cóstola, J.L.M. Hensen, Simulation-based support for product development of innovative building envelope components, Autom. Constr. 45 (2014) 86-95.

[10] S. Attia, M. Hamdy, W. O'Brien, S. Carlucci, Assessing gaps and needs for integrating building performance optimization tools in net zero energy buildings design, Energy Build. 60 (2013) 110-124. doi:10.1016/j.enbuild.2013.01.016.

[11] S. Attia, E. Gratia, A. De Herde, J.L.M. Hensen, Simulation-based decision support tool for early stages of zero-energy building design, Energy Build. 49 (2012) 2-15. doi:10.1016/j.enbuild.2012.01.028.

[12] IBPSA International Building Performance Simulation Association, (n.d.). http://www.ibpsa.org/ (accessed October 30, 2017).

[13] C. Maurer, C. Cappel, T.E. Kuhn, Progress in building-integrated solar thermal systems, Sol. Energy. (2016). doi:10.1016/j.solener.2017.05.065.

[14] EU - European Union, Regulation (EU) No 305/2011 of the European Parliament and of the Council of 9 March 2011 laying down harmonized conditions for the marketing of construction products and repealing Council Directive 89/106/EEC, Off. J. Eur. Unionf. (2011) 5-43.

[15] T.E. Kuhn, State of the art of advanced solar control devices for buildings, Sol. Energy. (2017). doi:10.1016/j.solener.2016.12.044.

[16] C. Maurer, D. Gasnier, T. Pflug, P. Plešec, J. Hafner, S. Jordan, T.E. Kuhn, First measurement results of a pilot building with transparent facade collectors, Energy Procedia. 48 (2014) 1385-1392. doi:10.1016/j.egypro.2014.02.156.

[17] A. Katsifaraki, B. Bueno, T.E. Kuhn, C. Maurer, Assessment of a photovoltaic thermal ( PVT ) prefabricated façade, in: Thermische Solarenergie, Staffelstein, 2014. doi:10.13140/2.1.1287.5527.

[18] M. Sala, THE INTELLIGENT ENVELOPE : THE CURRENT STATE OF THE ART, Renew. Energy. 5 (1994) 1039-1046.

[19] G. Quesada, D. Rousse, Y. Dutil, M. Badache, S. Hallé, A comprehensive review of solar facades. Transparent and translucent solar facades, Renew. Sustain. Energy Rev. 16 (2012) 2643-2651. 
[20] G. Quesada, D. Rousse, Y. Dutil, M. Badache, S. Hallé, A comprehensive review of solar facades. Opaque solar facades, Renew. Sustain. Energy Rev. 16 (2012) 2820-2832.

[21] K. Farkas, L. Maturi, A. Scognamiglio, F. Frontini, M. Wall, M. Lundgren, C. Roecker, Designing Photovoltaic Systems for Architectural Integration: Criteria and Guidelines for Product and System Developers. IEA SHC Task, 41, 2013.

[22] K. Farkas, M.C.M. Probst, M. Horvat, Barriers and Needs for Building Integration of Solar Thermal and Photovoltaics, Architecture. (n.d.).

[23] C. Cappel, W. Streicher, F. Lichtblau, C. Maurer, Barriers to the market penetration of façade-integrated solar thermal systems, Energy Procedia. 48 (2014) 1336-1344. doi:10.1016/j.egypro.2014.02.151.

[24] A. Prieto, U. Knaack, T. Auer, T. Klein, T. Klein, Solar façades - Main barriers for widespread façade integration of solar technologies, J. Facade Des. Eng. 5 (2017) 51-62. doi:10.7480/jfde.2017.1.1398.

[25] F. Favoino, M. Overend, Q. Jin, The optimal thermo-optical properties and energy saving potential of adaptive glazing technologies, Appl. Energy. 156 (2015) 1-15. doi:10.1016/j.apenergy.2015.05.065.

[26] S.H. Yoo, Simulation for an optimal application of BIPV through parameter variation, Sol. Energy. 85 (2011) 1291-1301. doi:10.1016/j.solener.2011.03.004.

[27] N.J.C.M. van der Borg, M.J. Jansen, Energy loss due to shading in a BIPV application, in: Proc. 3rd World Conf. Photovolt. Energy Convers., 2003: p. 2220-2222 Vol.3.

[28] C. Lamnatou, J.D. Mondol, D. Chemisana, C. Maurer, Modelling and simulation of Building-Integrated solar thermal systems: Behaviour of the system, Renew. Sustain. Energy Rev. 45 (2015) 36-51.

[29] C. Lamnatou, J.D. Mondol, D. Chemisana, C. Maurer, Modelling and simulation of Building-Integrated solar thermal systems: Behaviour of the coupled building/system configuration, Renew. Sustain. Energy Rev. 48 (2015) 178-191.

[30] C. Maurer, T.E. Kuhn, Variable g value of transparent facade collectors, Energy Build. 51 (2012) $177-184$. doi:10.1016/j.enbuild.2012.05.011.

[31] C. Maurer, C. Cappel, T.E. Kuhn, Simple models for building-integrated solar thermal systems, Energy Build. 103 (2015) 118-123. doi:10.1016/j.enbuild.2015.05.047.

[32] S. Robinson, Choosing the Right Model: Conceptual Modelling for Simulation, Proc. 2011 Winter Simul. Conf. (2011) 1423-1435.

[33] I. Gaetani, P. Hoes, J. Hensen, L M, Occupant behaviour in building energy simulation: towards a fit-forpurpose modelling strategy, Energy Build. 121 (2016) 188-204. doi:http://dx.doi.org/10.1016/j.enbuild.2016.03.038.

[34] D.R. Myers, Solar radiation modelling and measurements for renewable energy applications: Data and model quality, Energy. 30 (2005) 1517-1531. doi:10.1016/j.energy.2004.04.034.

[35] P.G. Loutzenhiser, H. Manz, C. Felsmann, P.A. Strachan, T. Frank, G.M. Maxwell, Empirical validation of models to compute solar irradiance on inclined surfaces for building energy simulation, Sol. Energy. 81 (2007) 254267. doi:10.1016/j.solener.2006.03.009.

[36] P.R. Tregenza, Subdivision of the sky hemisphere for luminance measurements, Light. Res. Technol. 19 (1987) 13-14. doi:10.1177/096032718701900103.

[37] R. Perez, R. Seals, J. Michalsky, All-weather model for sky luminance distribution-Preliminary configuration and validation, Sol. Energy. 50 (1993) 235-245. doi:10.1016/0038-092X(93)90017-I.

[38] C.F. Reinhart, O. Walkenhorst, Validation of dynamic RADIANCE-based daylight simulations for a test office with external blinds, Energy Build. 33 (2001) 683-697. doi:10.1016/S0378-7788(01)00058-5.

[39] G. Ward, R. Shakespeare, Rendering with RADIANCE. The Art and Science of Lighting Visualization, Morgan Kaufmann Publishers, 1998.

[40] J. Wienold, Daylight glare in offices., (2011). 
[41] A.W. Smith, A. Rohatgi, Ray tracing analysis of the inverted pyramid texturing geometry for high efficiency silicon solar cells, Sol. Energy Mater. Sol. Cells. 29 (1993) 37-49. doi:https://doi.org/10.1016/0927-0248(93)90090P.

[42] P. Campbell, M.A. Green, Light trapping properties of pyramidally textured surfaces, J. Appl. Phys. 62 (1987). doi:https://doi.org/10.1063/1.339189.

[43] T.E. Kuhn, Solar control: Comparison of two new systems with the state of the art on the basis of a new general evaluation method for facades with venetian blinds or other solar control systems, Energy Build. 38 (2006) 661-672. doi:10.1016/j.enbuild.2005.10.001.

[44] J.H. Klems, A new method for predicting the solar heat gain of complex fenestration systems II. Detailed description of the matrix layer calculation., ASHRAE Trans. 100 (1993).

[45] J.H. Klems, A new method for predicting the solar heat gain of complex fenestration systems I. Overview and derivation of the matrix layer calculation., ASHRAE Trans. 100 (1993).

[46] B. Maheu, G. Gouesbet, Four-flux models to solve the scattering transfer equation: special cases Appl. Opt. 25, 1122-1128 (1986), Appl. Opt. 25 (1986) 1122-1128. doi:https://doi.org/10.1364/AO.25.001122.

[47] B. Maheu, J.N. Letoulouzan, G. Gouesbet, Four-flux models to solve the scattering transfer equation in terms of Lorenz-Mie parameters, Appl. Opt. 23 (1984) 3353-3362. doi:https://doi.org/10.1364/AO.23.003353.

[48] A. Roos, P. Polato, P.A.V.A.N. Nijnatten, G. Hutchins, F. Olive, C. Anderson, ANGULAR-DEPENDENT OPTICAL PROPERTIES OF LOW-E AND SOLAR CONTROL WINDOWS - SIMULATIONS VERSUS MEASUREMENTS, 69 (2001) 15-26.

[49] B. Slovick, Z. Flom, L. Zipp, S. Krishnamurthy, Transfer matrix method for four-flux radiative transfer, Appl. Opt. 56 (2017) 5890. doi:10.1364/AO.56.005890.

[50] EN410, EN410 Glass in building. Determination of luminous and solar characteristics of glazing, (2011).

[51] A.P.A.F. Souka, H.H. Safwat, Determination of the optimum orientations for the double-exposure, flat-plate collector and its reflectors, Sol. Energy. 10 (1966) 170-174. doi:https://doi.org/10.1016/0038-092X(66)90004-1.

[52] P. Ambrosetti, J. Keller, Das neue Bruttowarmeertragsmodell fuverglaste Sonnenkollektoren, 1985.

[53] W.R. McIntire, Factored approximations for biaxial incident angle modifiers, Sol. Energy. 29 (1982) 315322. doi:https://doi.org/10.1016/0038-092X(82)90246-8.

[54] M. (Lawrence B.I.L. Martin, P. (Lawrence B.I.L. Berdahl, Characteristics of Infrared Sky Radiation in the United States, Sol. Energy. 33 (1984) 321-336. doi:https://doi.org/10.1016/0038-092X(84)90162-2.

[55] I. Beausoleil-Morrison, The adaptive coupling of heat and air flow modelling within dynamic whole-building simulation, Mech. Eng. Ph D (2000) 241. http://www.esru.strath.ac.uk/Documents/PhD/beausoleilmorrison_thesis.pdf.

[56] J.A. Clarke, Energy simulation in building design, Routeledge, Glasgow, UK, 2007.

[57] J.A. Clarke, Environmental System Performance, University of Strathclyde, Glasgow, UK, 1977. http://ethos.bl.uk/OrderDetails.do?uin=uk.bl.ethos.483348.

[58] C.G. Broyden, A Class of Methods for Solving Nonlinear Simultaneous Equations, Math. Comput. 19 (1965) 577-593. doi:http://doi.org/10.1090/S0025-5718-1965-0198670-6.

[59] EN 410: Glass in building - Determination of luminous and solar characteristics of glazing, (2011).

[60] ISO 15099, Thermal performances of windows, doors and shading devices - detailed calculations., (2003).

[61] N. Ito, K. Kimura, J. Oka, Field experiment study on the convective heat transfer coefficient on exterior surface of a building, ASHRAE Trans. 78 (1972) 184-191.

[62] T.M. McClellan, C.O. Pedersen, Investigation of outside heat balance models for use in a heat balance cooling load calculation procedure, in: ASHRAE Trans., American Society of Heating, Refrigerating and AirConditioning Engineers, Inc., Atlanta, GA (United States), Boston, MA (United States), 1997: pp. 469-484. 
[63] M. Yazdanian, J.H. Klems, Measurement of the exterior convective film coefficient for windows in low-rise buildings, in: ASHRAE Trans., New Orleans, 1994: pp. 1-15.

[64] M. Mirsadeghi, D. Cóstola, B. Blocken, J.L.M. Hensen, Review of external convective heat transfer coefficient models in building energy simulation programs: Implementation and uncertainty, Appl. Therm. Eng. 56 (2013) 134-151. doi:10.1016/j.applthermaleng.2013.03.003.

[65] R. Zhang, P.A. Mirzaei, J. Carmeliet, Prediction of the surface temperature of building-integrated photovoltaics: Development of a high accuracy correlation using computational fluid dynamics., Sol. Energy. 147 (2017) 151-163.

[66] J. Hartnett, W. Rohsenow, Handbook of heat transfer, New York, 1973.

[67] V.H. Heat Atlas, VDI-Gesellschaft Verfahrenstechnik und Chemieingenieurwesen., Second edi, Düsseldorf, 2010.

[68] EN673, EN 673 Glass in building - Determination of thermal transmittance (U value) - Calculation method, (2011).

[69] M. Hermann, Bionische Ansätze zur Entwicklung energieeffizienter Fluidsysteme für den Wärmetransport, Universität Karlsruhe (TH), 2005.

[70] C. Welz, C. Maurer, P. Di Lauro, G. Stryi-Hipp, M. Hermann, Mass flow, pressure drop, and leakage dependent modelling and characterization of solar air collectors., in: A. Häberle (Ed.), Energy Procedia, Proceedings of the 2nd International Conference on Solar Heating and Cooling for Buildings and Industry (SHC 2013), 2014: pp. 250-263. doi:https://doi.org/10.1016/j.egypro.2014.02.030.

[71] IEC, IEC 60904-3: 1989: Photovoltaic devices - Part 3: Measurement principles for terrestrial photovoltaic (PV) solar devices with reference spectral irradiance data, 1989.

[72] W. Heydenreich, B. Müller, C. Reise, Describing the World With Three Parameters: A New Approach to PV Module Power Modelling, 23rd Eur. Photovolt. Sol. Energy Conf. Exhib. 1-5 Sept. 2008, Val. Spain. 25 (2008) 2786-2789. doi:10.4229/23rdEUPVSEC2008-4DO.9.4.

[73] D.L. King, W.E. Boyson, J.A. Kratochvil, Photovoltaic array performance model, Sandia Rep. No. 20043535. 8 (2004) 1-19. doi:10.2172/919131.

[74] J. Sutterlueti, S. Ransome, R. Kravets, L. Schreier, Characterising PV modules under outdoor conditions:what's most important for energy yield, in: 26th Eur. Photovolt. Sol. Energy Conf. Exhib. - Proc. Most Inspiring Platf. Glob. PV Sol. Sect. ; CCH Congr. Cent. Int. Fair, Hamburg; Germany, WIP Renewable Energies, München, 2011.

[75] J.A. Gow, C.D. Manning, Development of a photovoltaic array model for use in power-electronics simulation studies, IEE Proc. - Electr. Power Appl. 146 (1999) 193-200. doi:10.1049/ip-epa:19990116.

[76] W. De Soto, S.A. Klein, W.A. Beckman, Improvement and validation of a model for photovoltaic array performance, Sol. Energy. 1 (2006) 78-88. doi:doi:10.1016/j.solener.2005.06.010.

[77] V.J. Chin, Z. Salam, K. Ishaque, Cell modelling and model parameters estimation techniques for photovoltaic simulator application: A review, Appl. Energy. (2015) 500-519.

[78] J.S. Stein, J. Sutterlueti, S. Ransome, C.W. Hansen, B.H. King, Outdoor PV Performance Evaluation of Three Different Models: Single-Diode, SAPM and Loss Factor Model, Sandia Natl. Lab. (2013).

[79] IEA SHC Task 41: Solar Energy and Architecture, Solar design of buildings for architects: Review of solar design tools: Subtask B: Methods and Tools for Solar Design, (n.d.).

[80] W. Sprenger, Electricity yield simulation of complex BIPV systems, Fraunhofer - Verlag, 2013. https://repository.tudelft.nl/islandora/object/uuid:3bd97b56-3edb-4071-8d5e-fe901b9d6e23?collection=research.

[81] J. Eisenlohr, H.R. Wilson, T.E. Kuhn, Detailed modelling of building-integrated photovoltaics - from component and environmental data to the system output, in: 33rd Eur. Photovolt. Sol. Energy Conf. Exhib. EU PVSEC, Amsterdam, The Netherlands, 2017. 
[82] Y.B. Assoa, L. Mongibello, A. Carr, B. Kubicek, M. Machado, J. Merten, S. Misara, F. Roca, W. Sprenger, M. Wagner, S. Zamini, T. Baenas, P. Malbranche, Thermal analysis of a BIPV system by various modelling approaches, Sol. Energy. 155 (2017) 1289-1299.

[83] P.I. Cooper, R. V. Dunkle, A non-linear flat-plate collector model, Sol. Energy. 26 (1981) 133-140. doi:10.1016/0038-092X(81)90076-1.

[84] T. Pflug, P. Di Lauro, T.E. Kuhn, C. Maurer, Evaluation of a simplified model for facade collectors, in: 13th Conf. Int. Build. Simul. Assoc. IBPSA, IBPSA, Chambery, France, 2013. doi:10.13140/2.1.4569.7925.

[85] T.E. Kuhn, Calorimetric determination of the solar heat gain coefficient $\mathrm{g}$ with steady-state laboratory measurements, Energy Build. 84 (2014) 388-402. doi:https://doi.org/10.1016/j.enbuild.2014.08.021.

[86] C. Maurer, W. Sprenger, M. Lämmle, T.E. Kuhn, Simple models for architecture with BIPVT or BIST, in: Conf. Adv. Build. Ski., Bern, Switzerland, 2015: pp. 159-163.

[87] T.E. Kuhn, Solar control: A general evaluation method for facades with venetian blinds or other solar control systems, Energy Build. 38 (2006) 648-660. doi:10.1016/j.enbuild.2005.10.002.

[88] T.E. Kuhn, S. Herkel, F. Frontini, P. Strachan, G. Kokogiannakis, Solar control: A general method for modelling of solar gains through complex facades in building simulation programs, Energy Build. 43 (2011) $19-27$. doi:10.1016/j.enbuild.2010.07.015.

[89] R.M.E. Valckenborg, W. Van der Wall, W. Folkerts, J.L.M. Hensen, A. De Vries, ZigZag structure in facade optimizes PV yield while aesthetics are preserved, in: 32rd Eur. Photovolt. Sol. Energy Conf. Exhib. (EU PVSEC), Munich, Germany, 2016: pp. 2481-2486.

[90] M. Boyd, Analytical model for solar irradiance near a planar vertical diffuse reflector - Formulation, validation, and simulations, Sol. Energy. 91 (2013) 79-92. doi:10.1016/j.solener.2013.01.015.

[91] R. Santbergen, V.A. Muthukumar, R.M.E. Valckenborg, W.J.A. van de Wall, A.H.M. Smets, M. Zeman, Calculation of irradiance distribution on PV modules by combining sky and sensitivity maps, Sol. Energy. 150 (2017) 49-54. doi:10.1016/j.solener.2017.04.036.

[92] Daysim, (n.d.). http://daysim.ning.com (accessed September 19, 2017).

[93] W. Sprenger, H.R. Wilson, T.E. Kuhn, Electricity yield simulation for the building-integrated photovoltaic system installed in the main building roof of the Fraunhofer Institute for Solar Energy Systems ISE, Sol. Energy. 135 (2016) 633-643. doi:10.1016/j.solener.2016.06.037.

[94] AIS, Active insulation, (n.d.). www.active-insulation.com (accessed September 19, 2017).

[95] F. Favoino, Q. Jin, M. Overend, Design and control optimisation of adaptive insulation systems for office buildings. Part 1: Adaptive technologies and simulation framework, Energy. 127 (2017) 301-309. doi:10.1016/j.energy.2017.03.083.

[96] Y.T. Chae, R.K. Strand, Modelling ventilated slab systems using a hollow core slab: Implementation in a whole building energy simulation program, Energy Build. 57 (2013) 165-175. doi:10.1016/j.enbuild.2012.10.036.

[97] M. Hermann, T.E. Kuhn, E. Rommel, Development of a multifunctional semi-transparent façade collector, in: EuroSun - 1st Int. Conf. Sol. Heating, Cool. Build., Libon, Portugal, 2008.

[98] C. Maurer, Theoretical and experimental analysis and optimization of semi-transparent solar thermal façade collectors, Fraunhofer Verlag, 2012.

[99] W. Beckman, L. Broman, A. Fiksel, S. Klein, E. Lindberg, M. Schuler, J. Thornton, TRNSYS the most complete solar energy system modelling and simulation software, Renew. Energy. 5 (1994) 486-488. doi:https://doi.org/10.1016/0960-1481(94)90420-0.

[100] C. Maurer, T. Baumann, M. Hermann, P. Di Lauro, S. Pavan, L. Michel, T.E. Kuhn, P. Berchtold, S.A. Permasteelisa, HEATING AND COOLING IN HIGH-RISE BUILDINGS USING FAÇADE- INTEGRATED TRANSPARENT SOLAR THERMAL COLLECTOR SYSTEMS Fraunhofer Institute for Solar Energy Systems , Freiburg, Germany Interpane Entwicklungs- und Beratungsgesellschaft, Lauenförde, Germany, Build. Simul. 2011. (2011) 14-16. 
[101] C. Maurer, T.E. Kuhn, Modelling of active solar building envelopes for cost-effective evaluation, 5 (2017) 75-82. doi:10.7480/jfde.2017.2.1740.

[102] C. Maurer, T. Baumann, M. Hermann, P. Di Lauro, S. Pavan, L. Michel, T.E. Kuhn, Heating and cooling in high-rise buildings using facade-integrated transparent solar thermal collector systems, J. Build. Perform. Simul. 6 (2013) 449-457. doi:10.1080/19401493.2013.766263.

[103] D. Rutten, Grasshopper - Algorithmic modelling for Rhino version 0.9.0076, (2017). http://www.grasshopper3d.com/ (accessed October 9, 2017).

[104] McNeel Robert and Associates, "Rhinoceros Version 5.0," 2015, (n.d.). https://www.rhino3d.com/.

[105] J.A. Jakubiec, C.F. Reinhart, DIVA 2.0: Integrating daylight and thermal simulations using rhinoceros 3D, DAYSIM and EnergyPlus, Proc. Build. Simul. 2011 12th Conf. Int. Build. Perform. Simul. Assoc. (2011) $2202-2209$. doi:10.1017/CBO9781107415324.004.

[106] R. Vier, Octopus, (n.d.). http://www.grasshopper3d.com/group/octopus (accessed October 9, 2017).

[107] M. Horvat, M. Wall, Solar Design of Buildings for Architects: Review of Solar Design Tools, 2012.

[108] ISO 52016-1:2017, ISO 52016-1:2017 Preview Energy performance of buildings -- Energy needs for heating and cooling, internal temperatures and sensible and latent heat loads, (2017).

[109] Passive House Project Package. Website of Passive House Institute, (2017). http://passivehouse.com/04_phpp/04_phpp.htm (accessed September 18, 2017).

[110] P. Sahlin, L. Eriksson, P. Groman, H. Johnsson, A. Shapovalov, M. Vuolle, Whole-building simulation with symbolic DAE equations and general purpose solvers, Build. Environ. 39 (2004) 949-958. doi:https://doi.org/10.1016/j.buildenv.2004.01.019.

[111] D.B. Crawley, L.K. Lawrie, F.C. Winkelmann, W.F. Buhl, Y.J. Huang, C.O. Pedersen, R.K. Strand, R.J. Liesen, D.E. Fisher, M.J. Witte, J. Glazer, EnergyPlus: Creating a new-generation building energy simulation program, Energy Build. 33 (2001) 319-331. doi:10.1016/S0378-7788(00)00114-6.

[112] J.A. Clarke, The ESP-r System, in: Energy Simul. Build. Des., 2nd ed., London, 2001: pp. 355-356.

[113] C. Maurer, T.E. Kuhn, Transparent solar thermal façade collectors : New Trnsys Type and first validation results, (2011). doi:10.13140/2.1.4373.1847.

[114] M. Hauer, W. Streicher, Gebäudegekoppelte Simulation fassadenintegrierter Kollektoren mit TRNSYS, in: OTTI - 23. Symp. Thermische Solarenergie, 2013.

[115] D. Saelens, Energy performance assessment of single storey multiple-skin facades, KU Leuven, 2002.

[116] D. Saelens, S. Roels, H. Hens, Strategies to improve the energy performance of multiple-skin facades, Build. Environ. 43 (2008) 638-650. doi:10.1016/j.buildenv.2006.06.024.

[117] M. Trčka, J. Hensen, L M, M. Wetter, Co-simulation of innovative integrated HVAC systems in buildings, J. Build. Perform. Simul. 2 (2009) 209-230. doi:http://dx.doi.org/10.1080/19401490903051959.

[118] M. Janak, Coupling Building Energy and Lighting Simulation, Fifth Int. IBPSA Conf. Sept. 8 - 10. (1997) $313-319$.

[119] E. Djunaedy, External coupling between energy simulation and computational fluid dynamics, (2005) 1168. doi:ISBN 90-6814-586-X NUR.

[120] M. Wetter, Co-simulation of building energy and control systems with the Building Controls Virtual Test Bed, J. Build. Perform. Simul. 4 (2011) 185-203. doi:http://dx.doi.org/10.1080/19401493.2010.518631.

[121] I. Beausoleil-Morrison, M. Kummert, F. MacDonald, R. Jost, T. McDowell, A. Ferguson, Demonstration of the new ESP-r and TRNSYS co-simulator for modelling solar buildings, Energy Procedia. 30 (2012) 505-514. doi:10.1016/j.egypro.2012.11.060.

[122] C. Maurer, W. Sprenger, S. Franz, J. Lodewijks, U. Rüppel, T.E. Kuhn, Machine code functions in BIM for cost-effective high-quality buildings, in: Proc. PowerSkin 2017, 2017. 